\title{
Experimental Study and In-depth Tensile Mechanism Analysis of Grouted Sleeve Lapping Conectors
}

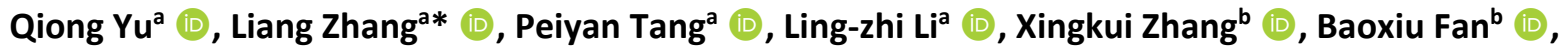 \\ Zhi Zhang ${ }^{c}$ (D), Zhenhai Chen ${ }^{c}$
}

a Department of Disaster Mitigation for Structures, Tongji University, Shanghai 200092, China; yiongyu2005@163.com, 1932537@tongji.edu.cn, tangpeiyan@tongji.edu.cn, tjlilingzhi@gmail.com

b Shanxi Construction Engineering Group Co., Ltd., Shanxi 030006, China; zhangxinkui2021@163.com, fanbaoxiu2@163.com, c Shanxi Erjian Group Co., Ltd., Taiyuan 030013, Shanxi, China; zhangzhi202108@163.com, fanbaoxiu2@139.com

* Corresponding author

https://doi.org/10.1590/1679-78256935

\begin{abstract}
To study the failure modes, bearing capacity, ductility, and sleeve strain of grouted sleeve lapping connectors, 36 specimens were tested under uniaxial tensile load. The test results show that the sleeves are under longitudinal tension at the beginning, which changes to longitudinal compression in the late stage of loading, and the changing load increases gradually with the lap length. The force transmission path and mechanical mechanism of the connectors are analyzed. The distribution and development process of longitudinal sleeve stress is analyzed based on the constitutive model stress, and it is found that the sleeve changes from longitudinal tension to longitudinal compression at the late loading stage, which is consistent with the test results. Based on the test, the calculation formulas of the ultimate bond strength and critical lap length of the grouted sleeve lapping connector are proposed. The research results lay a theoretical foundation for the application of grouted sleeve lapping connectors.
\end{abstract}

\section{Keywords}

Sleeve restraint; Sleeve strain; Transition of tension and compression strain; Loading path; Critical lap length

\section{Graphical Abstract}
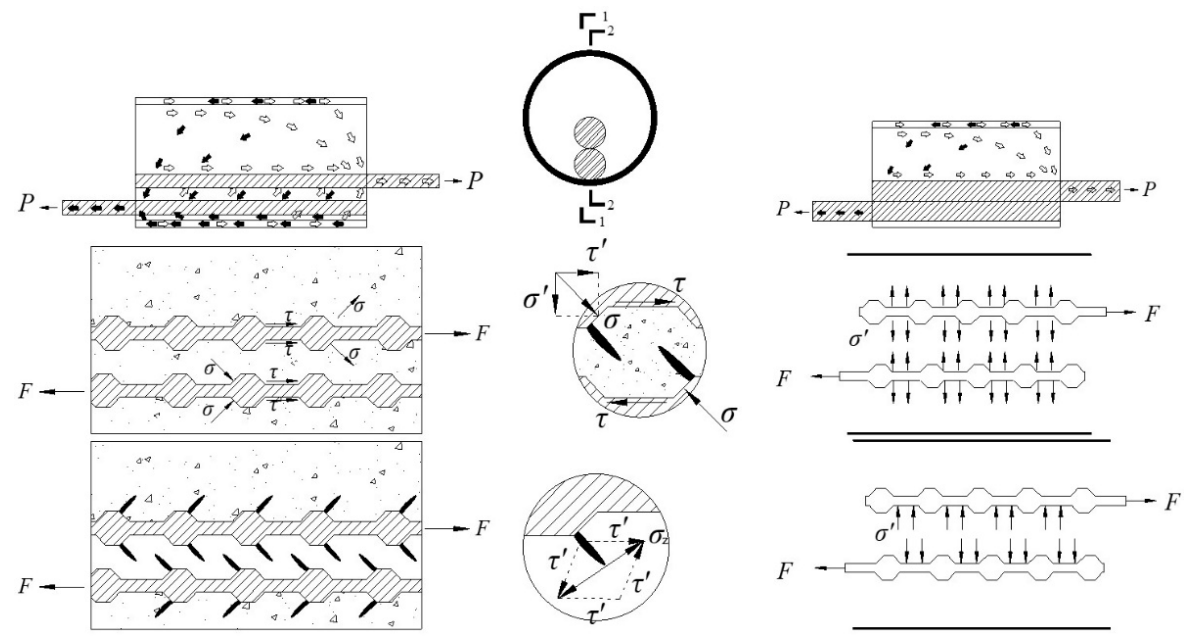

Received January 02, 2022. In revised form January 14, 2022. Accepted January 14, 2022. Available online January 17, 2022. https://doi.org/10.1590/1679-78256935 


\section{INTRODUCTION}

Cast-in-situ reinforced concrete is the most common method of construction for structural systems. Recently, there has been increased use of precast concrete members, whose design usually emulates the behavior of their cast-in-situ counterparts (Holden et al., 2003). Precast concrete structures have the advantages of convenience in construction, environmental friendliness, reduced costs, and easy of maintenance (Yee, 2001).

The connection between precast components plays a decisive role in whether a precast structure can perform its prescribed function. Ever since their invention by Alfred A. Yee (1968) in the late 1960s, grout-filled sleeves have been used to splice the reinforcing bars of adjacent components (Ling et al., 2008a; Ling et al., 2008b; Sayadi et al., 2014; Ling et al., 2014; Ameli et al., 2015; Popa et al., 2015; Lin and Wu, 2016; Wang et al., 2018; Liu et al., 2018; Xu et al., 2019; Lu et al., 2017). A grouted spliced sleeve, as shown in Figure 1, is pre-embedded in one component around the rebar requiring connection during fabrication. The other component is fabricated with the corresponding rebar extending from it, the two components are placed together, and the sleeve is filled with high-strength non-shrink grout from grout vents, using a grout pump (Henin and G. Morcous, 2015).

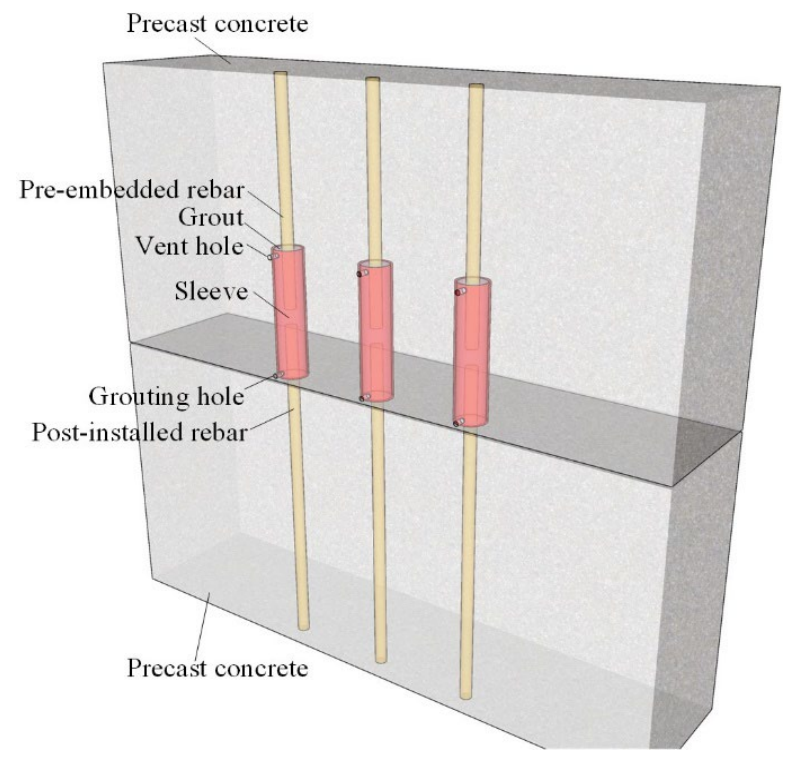

Figure 1 Grouted splice connector

A governing factor known as confinement significantly influences the anchorage bond and the required embedment length of rebar. The high bond strength of reinforcing bars can be achieved by confining the grout surrounding the bars, and lap splices or embedment lengths as short as seven times the bar diameter can achieve bar development when the appropriate grout compressive strength and confinement are provided (EINEA et al.,1995). Ling et al. found that the sleeve diameter and the bar embedded length of the grouted splice have significant effects on bond performance, i.e., a decrease in sleeve diameter and increase in bar embedded length will improve the bond performance (Ling et al., 2012). The modes of failure observed in the study consisted of bar slippage out of the connectors and bar fracture outside the proposed grouted sleeve connectors. An increase of anchorage length showed better performance, as the modes of failure changed from bar slippage for an anchorage length of $100 \mathrm{~mm}$ to bar fracture for an anchorage length of $200 \mathrm{~mm}$ (Alias et al., 2013).

Most grouted sleeves are designed to allow a maximum tolerance of $0.5 \mathrm{~mm}$ or less in the connection of the spliced bars, because a smaller sleeve inner diameter will provide greater confinement to achieve a higher bond strength between the bar and the grout, which increases the tensile capacity (Ling et al., 2012; Zheng et al., 2018). However, a small sleeve inner diameter always brings difficulty to the construction of precast structures. In engineering practice, the sleeves are usually designed one or two diameters larger than the diameter of the spliced bars to provide sufficient tolerance for the assembly of adjacent precast components. One problem of this design is that the connector's ability to transfer force is diminished by the incomplete fill of grout between the bar and the sleeve cavity. Moreover, the protruded bar in the precast component inevitably leans during transportation and construction, which is a serious problem, as workers must exert force to correct the inclination of the bars for insertion into the sleeves. Some workers cut off the inclined bar for ease of construction if the inclination is too great to correct, which weakens the connection performance of the splice. 
Then, many splice sleeves that accommodate current production practices with better tolerances, that are easy to produce, and that are more economical were invented (Sayadi et al., 2015; Hosseini et al., 2015; Wu et al., 2016; Hosseini and Rahman, 2016). For example, the spiral reinforcement sleeve has a spiral reinforcement bar welded to longitudinal steel bars to ensure mechanical interlocking at the contact surface between the grout and the sleeve connector. Due to the use of shear keys, the ultimate bonding force is about three times that of a normal sleeve (Seyed and Ahmad, 2013). To solve the construction difficulties and lower the production cost of the sleeve connectors, Yu developed a grouted sleeve lapping connector (Yu, 2014). As shown in Figure 2, a type-I sleeve was cut from a standard pipe section, and thus does not require additional fabrication. It was employed to connect two overlapping steel bars, and the high strength grout in the sleeve performed as the force transmission media. The grouted sleeve lapping connector has a construction process similar to that of the grouted splice connector, but it has the advantage of a large sleeve inner diameter, up to $70 \mathrm{~mm}$, which gives a considerable fault tolerance to components during construction. Prior to the casting of the components of a precast concrete connection, the sleeve is fixed at one end of a component with a steel bar spot welded to the inner surface to facilitate assembly, and the other component will be connected to it. During construction, the steel bar from the other component is inserted in the sleeve, and the grout is injected in the sleeve through the grouting hole until the sleeve cavity is full.

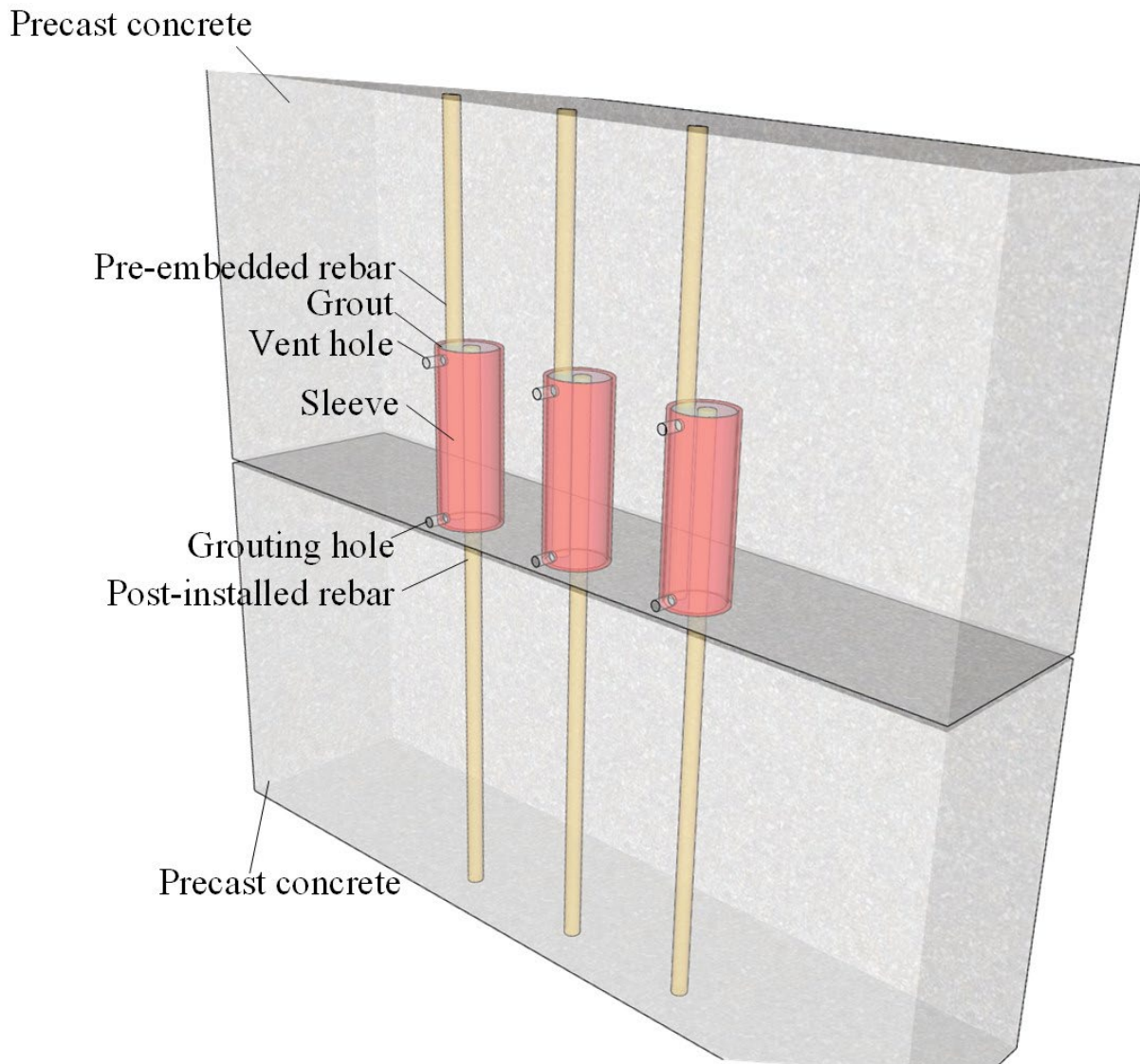

Figure 2 Type-I grouted sleeve lapping connector

Test results show that the grouted sleeve lapping connector can effectively transfer the vertical stress of reinforcement bars (Yu, 2014). Bar tensile failure and bar-grout bond failure are typical failure modes of grouted sleeve lapping connectors; grout-sleeve slip and sleeve tensile failure were not shown (Yu and Xu, 2017). Test results showed that on the premise of ensuring strength, the grouted sleeve lapping connector not only reduced the length of the connector compared with its counterpart but had better ductility. In another test study, the tensile capacity of a grouted sleeve lapping connector was found to be 2.45 times that of a grouted splice connector (Yu et al., 2019). It is more convenient to insert the reinforcement bar in a grouted sleeve lapping connector than a grouted splice connector during assembly (Yu et al., 2016).

Research on grouted sleeve lapping connectors is still from the macro aspect, and mesoscopic, mechanistic, and regular research results are still lacking. For example, the tensile and compressive mechanisms of the grouted sleeve lapping connector are not clear yet, and the strain mechanism requires study, especially the longitudinal strain. 
In this paper, tensile tests of 36 grouted sleeve lapping connectors were carried out. The longitudinal and hoop stress-strain curves of the sleeve, the stress-strain curves of the bars inside and outside the sleeve, stiffness, elongation ratio, and ductility of the specimens are analyzed with the diameter and lap length of the steel bar as research parameters, and the force transfer path and stress mechanism of the connector are analyzed. A calculation equation of ultimate bond strength and critical lap length is proposed, providing a theoretical basis for the design of the grouted sleeve lapping connector.

\section{EXPERIMENTAL PROGRAM}

\subsection{Test design}

$\mathrm{H}-40$ grouting material was used in this test. According to Methods of testing cements-determination of strength (Bureau of Quality and Technical Supervision of the People's Republic of China, 1999), the compressive strength of the $40 \mathrm{~mm} \times 40 \mathrm{~mm} \times 160 \mathrm{~mm}$ specimens was $61.6 \mathrm{MPa}$, and the flexural strength was 7.2 MPa. The mean value of the splitting tensile strength of the $150 \mathrm{~mm} \times 150 \mathrm{~mm}$ specimen was $3.7 \mathrm{MPa}$.

The grade of the steel bar was HRB400, where HRB indicates high yield deformed steel bars (China, 2010). The yield strength from the material properties' test of steel bars is presented in Table 1.

The sleeves were made of Q235B seamless steel tube. Dog bone specimens were made for unidirectional tensile tests. The tested yield strength was above $235 \mathrm{MPa}$, the tensile strength was between $375 \mathrm{MPa}$ and $500 \mathrm{MPa}$, and the elongation after fracture was greater than $25 \%$.

Table 1 Material properties of steel bar

\begin{tabular}{cccccc}
\hline $\begin{array}{c}\text { Diameter of Steel } \\
\text { bar }(/ \mathbf{m m})\end{array}$ & $\begin{array}{c}f_{\mathrm{yk}} \\
(/ \mathrm{MPa})\end{array}$ & $\begin{array}{c}f_{\mathrm{uk}} \\
(/ \mathrm{MPa})\end{array}$ & $\overline{\boldsymbol{\varepsilon}}_{\mathrm{yk}}$ & $\overline{\boldsymbol{\varepsilon}}_{\mathrm{uk}}$ & $\overline{\boldsymbol{R}}_{\mathrm{dk}}$ \\
\hline 20 & 448.8 & 625.1 & 0.018 & 0.099 & 5.38 \\
22 & 441.8 & 631.5 & 0.018 & 0.096 & 5.37 \\
25 & 426.5 & 599.8 & 0.020 & 0.120 & 6.07 \\
\hline
\end{tabular}

\subsection{Design and measurement of specimen}

During the test, the connector was in the most unfavorable condition (without lateral restraint). The reserved steel bar was spot welded at both ends of the sleeve (fixing the position of the steel bar), and the other steel bar was inserted close to the reserved steel bar and placed along the axial direction of the sleeve. The sleeve was then filled with nonshrinkage grout. Since the two steel bars were not in the same straight line and there was no lateral constraint outside the sleeve, specimen deflection, as shown in Figure 3, occurred during the loading process, resulting in a tendency of the two steel bars in the sleeve to be in the same straight line.

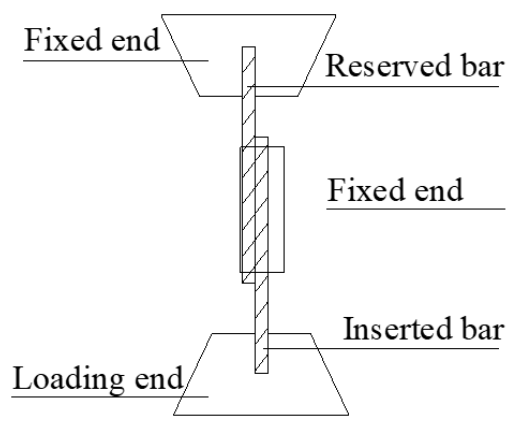

(a) Before loading

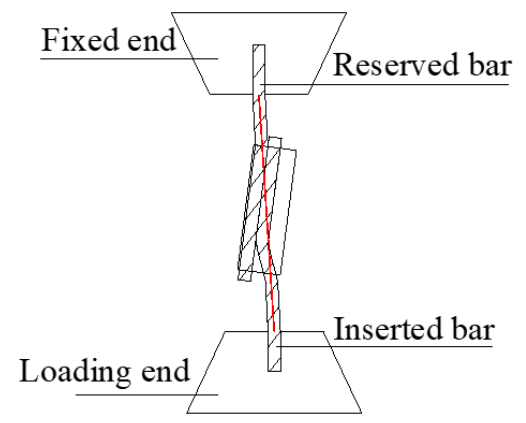

(b) After loading

Figure 3. Deflection of specimen after loading

There were 12 sets of specimens. The inner diameter $D$ of the sleeve was $79 \mathrm{~mm}$, and the wall thickness $t$ was $3.5 \mathrm{~mm}$. The variables in the experiment were the steel bar diameter $\mathrm{d}(20 \mathrm{~mm}, 22 \mathrm{~mm}, 25 \mathrm{~mm})$ and lap length L (6d, $8 \mathrm{~d}$, $10 \mathrm{~d}, 12.5 \mathrm{~d}$ ). Figure 4 shows a schematic diagram of the specimens. 


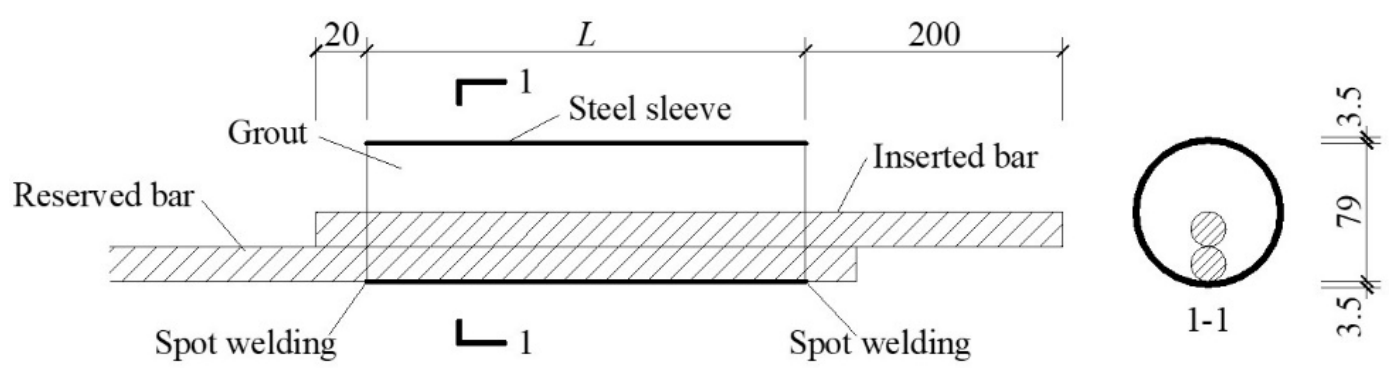

Figure 4. Schematic diagram of specimen(unit: $\mathrm{mm}$ )

Strain gauges SG1 SG4 were placed along the longitudinal direction of the reserved and inserted steel bars, and strain gauges SG9 SG14 were placed along the longitudinal direction of the sleeve. SG11 SG14 were only used for specimens with steel bar diameter $d=25 \mathrm{~mm}$, SG9 and SG10 measured the longitudinal strain in the middle section of the sleeve, SG11 and SG12 were on the one-third-length sections, and SG13 and SG14 were on the one-sixth length away from the sleeve end. Strain gauges SG5 SG8 were circumferentially arranged along the sleeve. Locations of strain gauges are shown in Figure 5.

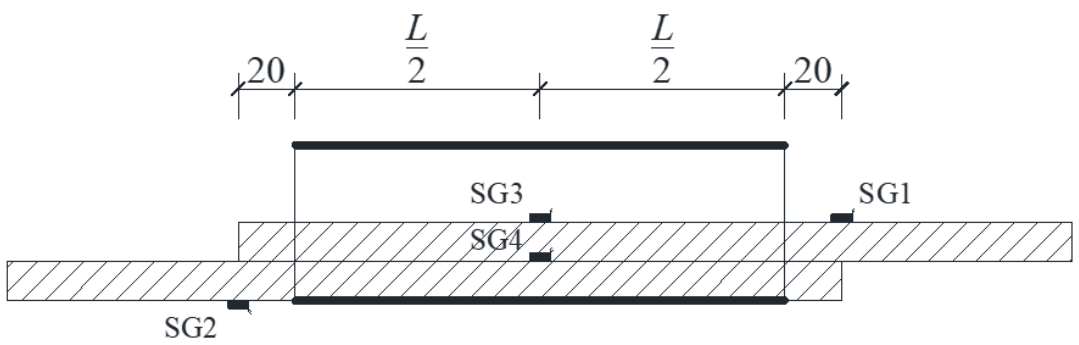

(a) Strain gauges on steel bars

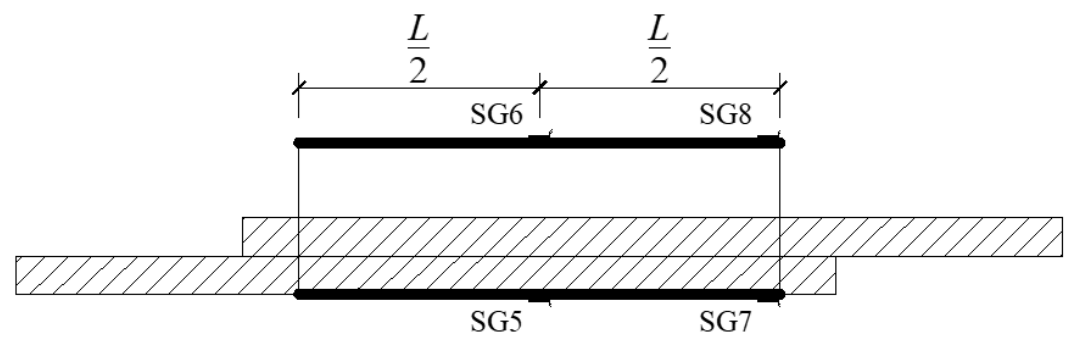

(b) Strain gauges in the hoop direction of the sleeve

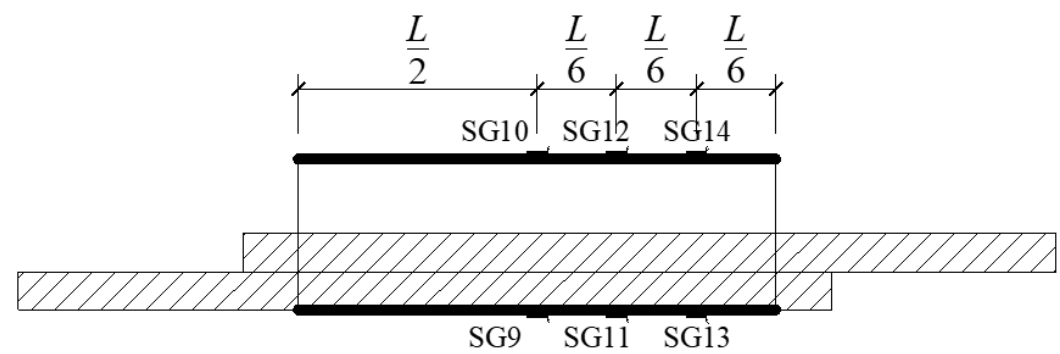

(c) Strain gauges in the longitudinal direction of the sleeve

Figure 5 Location of strain gauges(unit: $\mathrm{mm}$ )

\subsection{Experimental setup}

As shown in Figure 6, the universal testing machine at Tongji University was used as a loading device. A loading rate of $1 \mathrm{kN} / \mathrm{s}$ was employed before the load reached the load value specified in Table 2 (close to the yield load of the steel bars), and then a loading rate of $10 \mathrm{~mm} / \mathrm{min}$ was used until the specimen was damaged. 

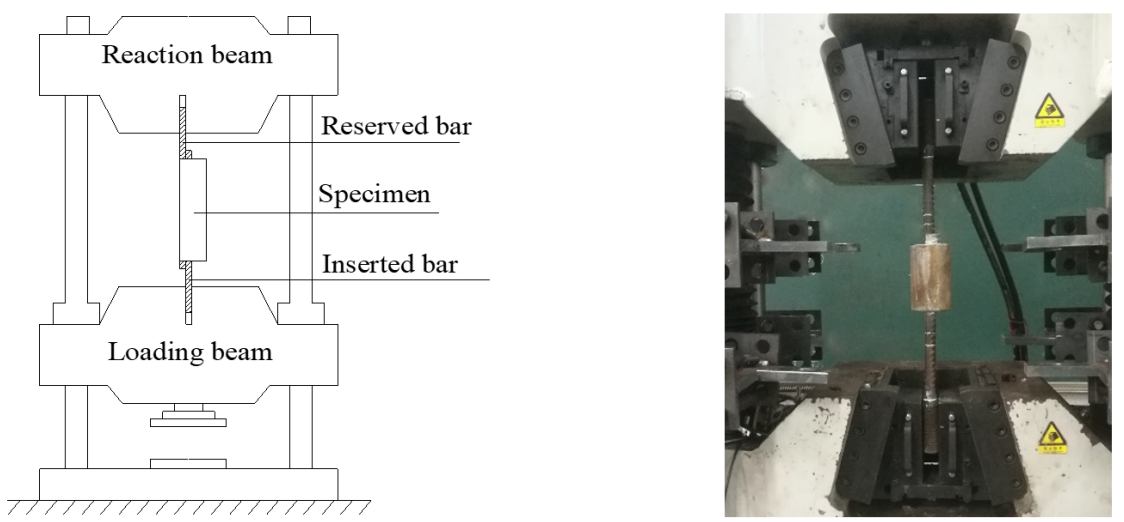

Figure 6 Setup of the test

Table 2 Loading load

\begin{tabular}{cccc}
\hline No & Diameter of Steel bar $(/ \mathbf{m m})$ & Load $(/ \mathbf{k N})$ \\
\hline 1. & 20 & 130 \\
2. & 22 & 160 \\
& 25 & 25 & 200 \\
\hline
\end{tabular}

\section{EXPERIMENTAL RESULTS}

\subsection{Failure modes}

As shown in Figure 7 and Figure 8, there are failure modes of specimens: the steel bar is pulled out of the sleeve, or it is broken.

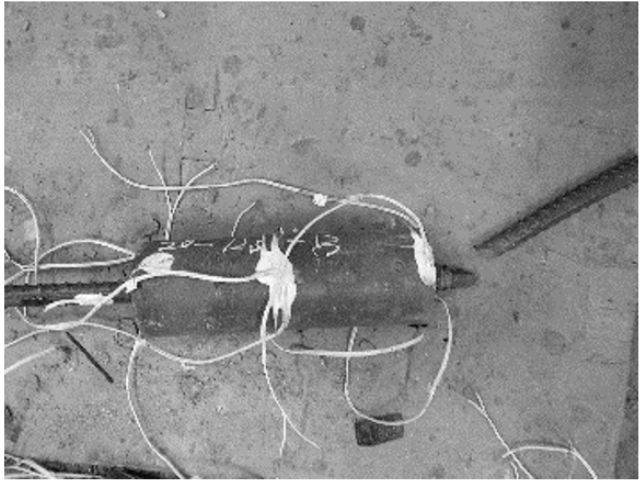

(a) Bar failure

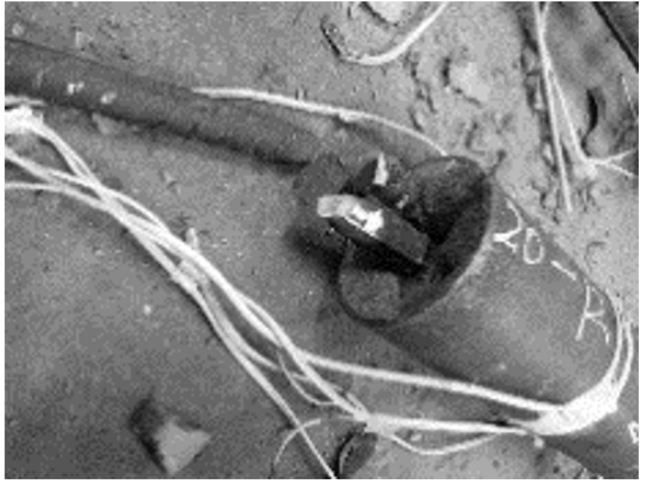

(b) Grout failure of loading end

Figure 7 Bar tensile failure of specimen

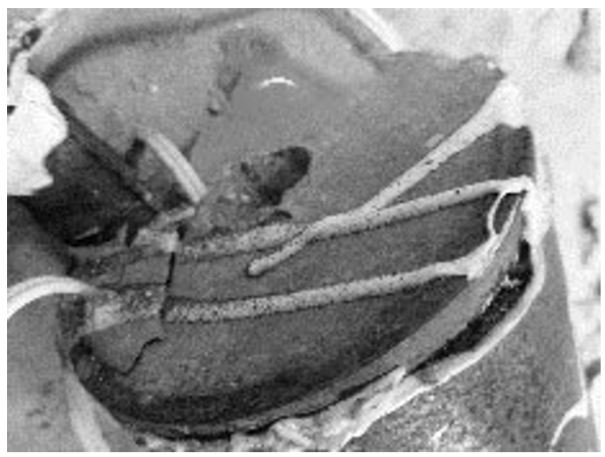

(a) Bar failure of fixed end

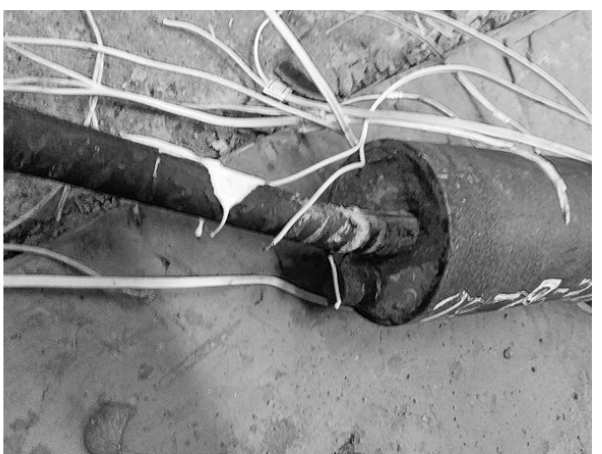

(b) Grout failure of fixed end

Figure 8 Bar-grout failure of specimen 
For specimens with lap length $L=6 d$, the failure mode is steel bar pull-out. When the specimen reaches the ultimate strength, the steel bar is pulled from the grouting material without yielding. The bearing capacity of the connector then drops rapidly, and eventually, the connector is destroyed because of slippage of the steel bar.

Steel bar pull-out failure also occurred for specimens with lap length $L$ of $8 d$, and most with lap length $10 d$, but unlike specimens with $L=6 \mathrm{~d}$, the steel bar would yield and strengthen before the specimen reached the ultimate state of bearing capacity.

For specimens with $L=12.5 \mathrm{~d}$ and a few with $\mathrm{L}=10 \mathrm{~d}$, the connector was destroyed, with the steel bar being broken at the section outside the sleeve. The grouting material at the end of the sleeve had an oblique failure but had little effect on the bearing capacity of the specimen, which mainly depended on the mechanical properties of the steel bar.

There was also a difference between the damage modes of inserted and reserved bars. As shown in Figure 8(a), the damage of a reserved bar was mostly grout cracking between the two steel bars, while the damage of an inserted bar was mainly local squeezing and crushing of the grout between the steel bar and the sleeve, as shown in Figure 7(b) and Figure 8(b), and grout damage was more serious than failure of the reserved bar. As shown in Figure 9, the reserved steel bar was close to the sleeve; so, the sleeve had a greater restraint effect on it, while the inserted bar was slightly farther from the sleeve; so, the sleeve had less restraint. Therefore, the inserted steel bar deformed greatly, and the surrounding grouting material was damaged seriously.

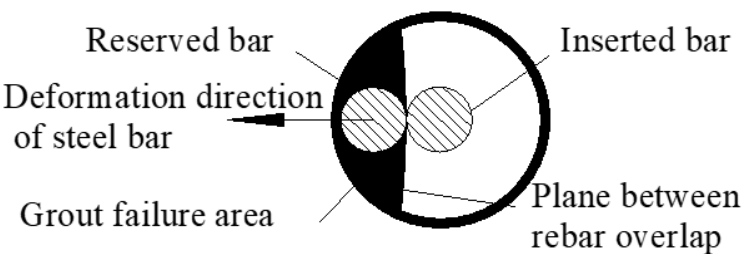

(a) Fixed end

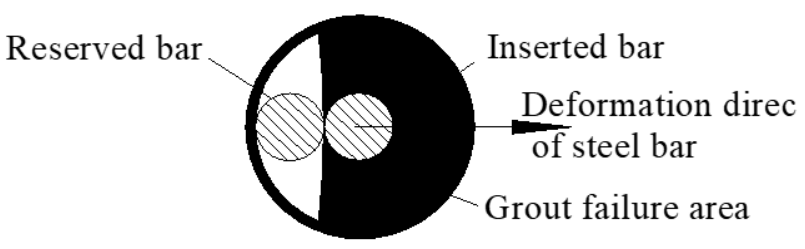

(b) Loading end

Figure 9 Local deformation at both ends of specimen

\subsection{Bearing capacity}

Table 3 presents the failure pattern, yield strength $f_{y}$, ultimate tensile strength $f_{u}$ obtained in the test, the ratio of $f_{y}$ to the standard yield strength $f_{y k}$, and the ratio of $f u$ to $f_{y}$ (the ratio of tensile strength to yield point) of each specimen.

The Technical specification for grout sleeve splicing of rebars: JGJ 355-2015 (Ministry of Housing and UrbanRural Construction of the People's Republic of China, 2015) stipulates that the ratio of the tensile strength of the connector to the standard value of the tensile strength of the connected steel bar, $f_{u} / f_{u k}$, should be greater than 1 , and the steel bar should be broken outside the connector when it is damaged. In other words, the ratio $f_{y} / f_{y k}$, i.e., the strength of the connector to that of the connected steel bar, should be greater than 1 . The Code for Seismic Design of Buildings (Ministry of Construction of The People's Republic of China, 2010) stipulates that the ratio $f_{u} / f_{y}$ computed by the measured value of the tensile strength of the steel bar to its measured value of the yield strength should not be less than 1.25, and the ratio of the measured value of the steel bar yield strength to the standard value of the yield strength, $f_{y} / f_{y k}$, should not be greater than 1.3 . Specimens with a sleeve length of $12.5 \mathrm{~d}$ in this test met the above requirements.

Figure 10 shows the influence of steel bar diameter and lap length on the ultimate bearing capacity of the specimen. It can be seen that the ultimate bearing capacity of the specimen increases with the diameter of the steel bar. This is mainly because the contact area between the steel bar and the grouting material increases with the diameter of the steel bar, which improves the bond strength. When the steel bar diameter remains the same and slip failure occurs (lap length at $10 \mathrm{~d}$ and below), the bearing capacity of the specimen increases with the lap length.

Figure 11 shows the influence of the steel bar diameter and lap length on the ultimate bond strength of the specimens (the failure mode of specimens with L equal to $12.5 \mathrm{~d}$ is the steel bar breaking; so, they are not included). The steel bar diameter and steel lap length are found to have little effect on the average ultimate bond strength of the specimen. 
Table 3 Test results

\begin{tabular}{|c|c|c|c|c|c|c|c|c|c|}
\hline Specimen & Failure pattern & $f_{\mathrm{y} / \mathrm{Mpa}}$ & $f_{\mathrm{u} / \mathrm{Mpa}}$ & $f_{\mathrm{y}} / f_{\mathrm{yk}}$ & $f_{\mathrm{u}} / f_{\mathrm{y}}$ & $f_{\mathrm{u}} / f_{\mathrm{uk}}$ & $\varepsilon_{\mathrm{y}}$ & $\varepsilon_{\mathrm{u}}$ & $R_{\mathrm{d}}$ \\
\hline $20-6-1$ & steel bar pulled out & - & 438 & - & - & 0.7 & - & 0.04 & - \\
\hline $20-6-2$ & steel bar pulled out & - & 454 & - & - & 0.73 & - & 0.039 & - \\
\hline $20-6-3$ & steel bar pulled out & - & 409 & - & - & 0.65 & - & 0.039 & - \\
\hline $22-6-1$ & steel bar pulled out & - & 402 & - & - & 0.64 & - & 0.041 & - \\
\hline $22-6-2$ & steel bar pulled out & - & 391 & - & - & 0.62 & - & 0.045 & - \\
\hline $22-6-3$ & steel bar pulled out & - & 380 & - & - & 0.6 & - & 0.034 & - \\
\hline $25-6-1$ & steel bar pulled out & - & 360 & - & - & 0.6 & - & 0.037 & - \\
\hline $25-6-2$ & steel bar pulled out & - & 387 & - & - & 0.65 & - & 0.041 & - \\
\hline $25-6-3$ & steel bar pulled out & - & 365 & - & - & 0.61 & - & 0.037 & - \\
\hline $20-8-1$ & steel bar pulled out & 457.7 & 575 & 1.15 & 1.26 & 0.92 & 0.033 & 0.062 & 1.9 \\
\hline $20-8-2$ & steel bar pulled out & 451.3 & 597 & 1.13 & 1.32 & 0.96 & 0.033 & 0.073 & 2.19 \\
\hline $20-8-3$ & steel bar pulled out & 450.4 & 583 & 1.13 & 1.29 & 0.93 & 0.033 & 0.069 & 2.07 \\
\hline $22-8-1$ & steel bar pulled out & 448.6 & 575 & 1.12 & 1.28 & 0.91 & 0.031 & 0.062 & 1.97 \\
\hline $22-8-2$ & steel bar pulled out & 444.4 & 603 & 1.11 & 1.36 & 0.95 & 0.038 & 0.076 & 2.02 \\
\hline $22-8-3$ & steel bar pulled out & 446.7 & 585 & 1.12 & 1.31 & 0.93 & 0.044 & 0.077 & 1.77 \\
\hline $25-8-1$ & steel bar pulled out & 444.3 & 532 & 1.11 & 1.2 & 0.89 & 0.034 & 0.055 & 1.64 \\
\hline $25-8-2$ & steel bar pulled out & 446.9 & 546 & 1.12 & 1.22 & 0.91 & 0.039 & 0.067 & 1.7 \\
\hline $25-8-3$ & steel bar pulled out & 444.3 & 523 & 1.11 & 1.18 & 0.87 & 0.04 & 0.061 & 1.54 \\
\hline $20-10-1$ & Steel bar break & 451.3 & 631 & 1.13 & 1.4 & 1.01 & 0.03 & 0.109 & 3.68 \\
\hline $20-10-2$ & steel bar pulled out & 452.3 & 627 & 1.13 & 1.39 & 1 & 0.026 & 0.091 & 3.5 \\
\hline $20-10-3$ & steel bar pulled out & 457.7 & 601 & 1.14 & 1.31 & 0.96 & 0.031 & 0.072 & 2.34 \\
\hline $22-10-1$ & Steel bar break & 449.4 & 644 & 1.12 & 1.43 & 1.02 & 0.033 & 0.111 & 3.39 \\
\hline $22-10-2$ & steel bar pulled out & 450.9 & 644 & 1.13 & 1.43 & 1.02 & 0.027 & 0.11 & 4.13 \\
\hline $22-10-3$ & steel bar pulled out & 450.1 & 632 & 1.13 & 1.4 & 1 & 0.028 & 0.072 & 2.62 \\
\hline $25-10-1$ & steel bar pulled out & 445.1 & 622 & 1.11 & 1.4 & 1.04 & 0.029 & 0.105 & 3.68 \\
\hline $25-10-2$ & steel bar pulled out & 450 & 590 & 1.13 & 1.31 & 0.98 & 0.039 & 0.091 & 2.34 \\
\hline $25-10-3$ & steel bar pulled out & 446.7 & 604 & 1.12 & 1.35 & 1.01 & 0.034 & 0.087 & 2.52 \\
\hline $20-12.5-1$ & Steel bar break & 453.9 & 633 & 1.13 & 1.39 & 1.01 & 0.024 & 0.103 & 4.3 \\
\hline $20-12.5-2$ & Steel bar break & 457.4 & 637 & 1.14 & 1.39 & 1.02 & 0.028 & 0.108 & 3.87 \\
\hline $20-12.5-3$ & Steel bar break & 452.6 & 630 & 1.13 & 1.39 & 1.01 & 0.023 & 0.095 & 4.07 \\
\hline $22-12.5-1$ & Steel bar break & 448.8 & 642 & 1.12 & 1.43 & 1.02 & 0.03 & 0.1 & 3.31 \\
\hline $22-12.5-2$ & Steel bar break & 448.8 & 643 & 1.12 & 1.43 & 1.02 & 0.024 & 0.096 & 3.96 \\
\hline $22-12.5-3$ & Steel bar break & 446.2 & 643 & 1.12 & 1.44 & 1.02 & 0.029 & 0.097 & 3.38 \\
\hline $25-12.5-1$ & Steel bar break & 440.4 & 618 & 1.1 & 1.4 & 1.03 & 0.031 & 0.11 & 3.57 \\
\hline $25-12.5-2$ & Steel bar break & 442.5 & 617 & 1.11 & 1.39 & 1.03 & 0.031 & 0.114 & 3.7 \\
\hline $25-12.5-3$ & Steel bar break & 445.5 & 617 & 1.11 & 1.38 & 1.03 & 0.028 & 0.112 & 4.05 \\
\hline
\end{tabular}

Note: Take '20-6-1' as an example, ' 20 ' means the diameter of steel bar is $20 \mathrm{~mm}$, ' 6 ' means the lap length $\mathrm{L}$ is $6 \mathrm{~d}$, ' 1 ' means the No.1 specimen.

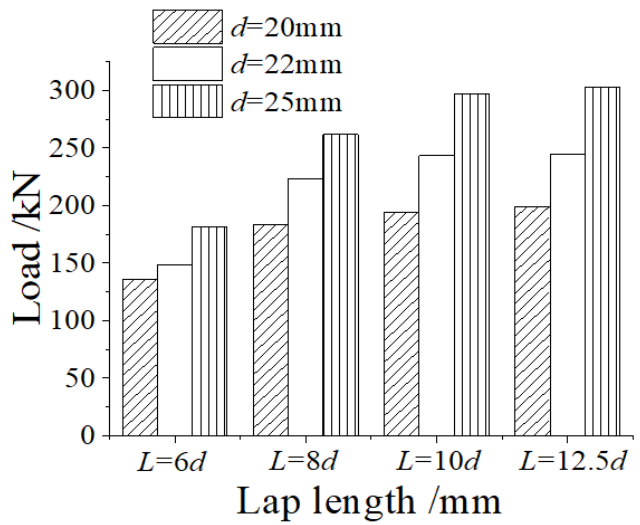

Figure 10 Effect of bar diameter and lap length on ultimate bear capacity of specimen 


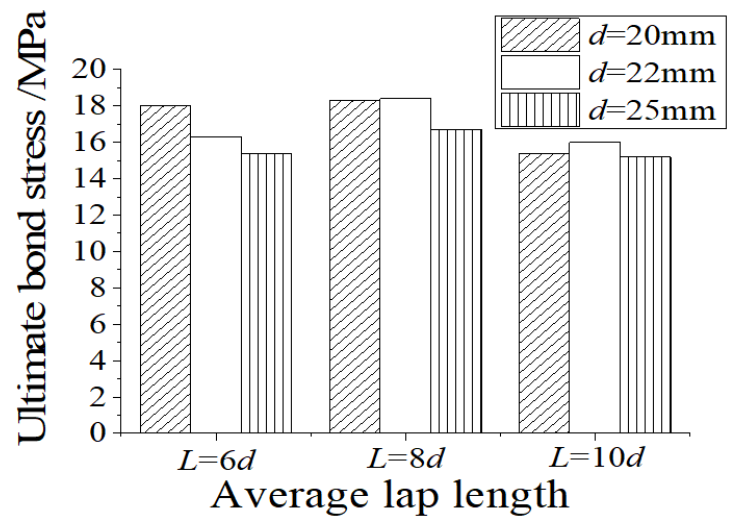

Figure 11 Effect of bar diameter and lap length on ultimate bound strength of specimen

\subsection{Load-average strain curve}

Figures $12(\mathrm{a})-(\mathrm{c})$ show the comparison between the representative load-average strain curve and the steel bar property test curve. The average strain is the ratio of the relative displacement of the two loading points of the test specimen to the initial distance between the loading points.

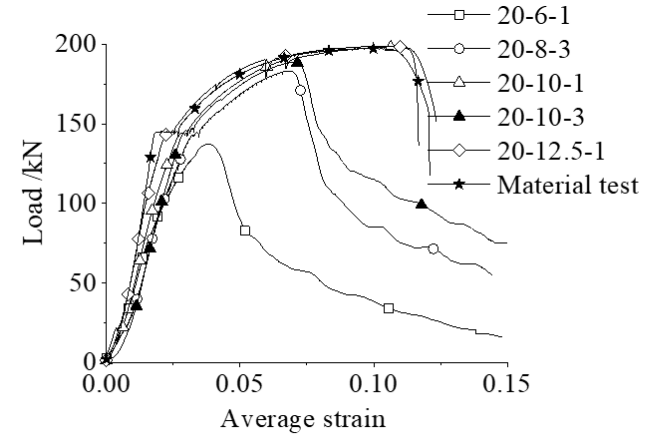

(a) $d=20 \mathrm{~mm}$

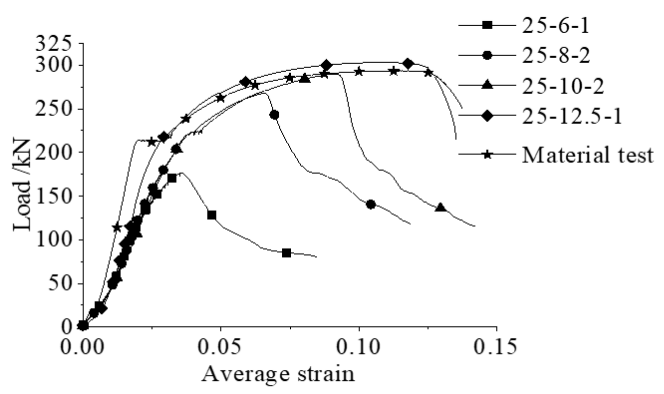

(c) $d=25 \mathrm{~mm}$

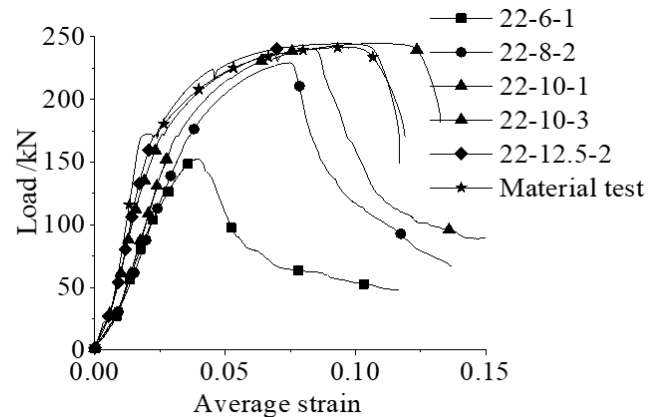

(b) $d=22 \mathrm{~mm}$

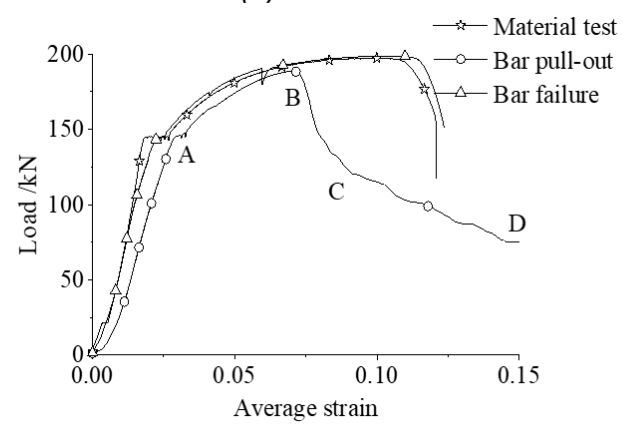

(d) Typical curve

Figure 12 Load- stain curves

Figure 12(d) shows the comparison of the steel material property test curve and load-average strain curve of the two typical failure modes of the specimens: steel bar pull-out and steel bar fracture. The curves are basically consistent, indicating that the performance of the steel bar is fully utilized. However, when a specimen failing in steel slip reaches its ultimate bearing capacity, due to insufficient anchoring capacity, slippage occurs between the steel bar and the grouting material, and the curve descends rapidly (section BC), followed by a gentle descent (section CD). At this stage, the friction between the steel bar and the grouting material plays a major part.

At a certain steel bar diameter, the lap length increases with that of the initial stiffness of the specimen. This is mainly because the average bonding force of the specimen decreases with the increase of the lap length; thus, the compression deformation of the grouting material between the steel bars and the micro-slip of the steel bars caused by local crushing of grout are both smaller. 


\subsection{Yield strain, elongation ratio, and displacement ductility coefficient}

Tables 3, 4 and 5 present the yield strain, elongation (ultimate strain), and displacement ductility coefficient of the specimens. The elongation of the connector is the ratio of the displacement between the two loading points under the maximum force to the initial distance between the two loading points, i.e., the average strain of the joint under the ultimate load. The displacement ductility coefficient is $R_{d}=\delta_{u} / \delta_{y}$, where $\delta_{u}$ is the displacement corresponding to the ultimate bearing capacity of the specimen, and $\delta_{y}$ is its yield displacement.

The yield strains of the steel bar sliding specimen and tensile fracture specimen were $0.0260-0.0435$ and $0.0234-$ 0.0326 , respectively. The yield strain of the tensile fracture specimen was greater than that of the steel bar test (about 0.0185), mainly because of the deflection of the test connector, which led to an increase in the deformation between the two loading points.

The elongation ratios of the steel bar sliding specimen were between $3.4 \%$ and $10.97 \%$, and those of the tensile fracture specimen were between $9.53 \%$ and $11.43 \%$. The elongation ratios of the tensile fracture specimens were similar to those of the steel material property test, and both were about $10 \%$.

The displacement ductility coefficients of the steel bar sliding specimen were 1.54-4.13, while those of the tensile fracture specimens were between 3.31 and 4.30 . So, the displacement ductility coefficients of the tensile fracture specimens were smaller than those of the steel material property test.

In the tensile process of the specimen, the deflection of the sleeve will cause a displacement increment between the loading points of the steel bar at both ends of the sleeve. When the load reaches the yield point, this displacement increment caused by sleeve deflection accounts for a larger portion of the specimen's yield displacement. However, when the ultimate load is reached, due to factors such as elongation and slippage of the steel bar, the proportion of the displacement increment of sleeve deflection becomes smaller, resulting in a slight decrease in the displacement ductility coefficient of the specimen. In an engineering structure, due to the constraint of the concrete around the sleeve on the deflection of the connector, there is no such factor to reduce the ductility. According to test results [28], after adding an effective anti-deflection device, the ductility coefficients of the $8 \mathrm{~d}, 10 \mathrm{~d}$, and $12 \mathrm{~d}$ tensile specimens were $3.81,3.66$, and 4.33 , respectively. It can be seen that the ductility reduction caused by deflection is very small and almost negligible.

Tables 4 and 5 present the average values of the elongation ratio and displacement ductility coefficient, respectively, of the specimens, from which it can be seen that when the steel bar diameter was the same, the greater the lap length, the greater the elongation ratio and displacement ductility coefficient of the specimen. This is because, as the lap length increases, the failure mode of the specimen changes from steel bar pull-out to steel bar failure. The steel bar reaches yield and develops toward the strengthening stage, and the more fully the deformation of the steel bar develops, the greater the elongation ratio and displacement ductility coefficient.

Table 4 Elongation of specimen

\begin{tabular}{cccc}
\hline \multirow{2}{*}{ Lap length } & \multicolumn{3}{c}{ Steel bar diameter $(/ \mathbf{m m})$} \\
\cline { 2 - 4 } & $\mathbf{2 0}$ & $\mathbf{2 2}$ & $\mathbf{2 5}$ \\
\hline$L=6 d$ & 0.039 & 0.040 & 0.038 \\
$L=8 d$ & 0.068 & 0.072 & 0.061 \\
$L=10 d$ & 0.090 & 0.097 & 0.094 \\
$L=12.5 d$ & 0.102 & 0.098 & 0.112 \\
\hline
\end{tabular}

Table 5 Displacement ductility coefficient of specimen

\begin{tabular}{cccc}
\hline \multirow{2}{*}{ Lap length } & \multicolumn{3}{c}{ Steel bar diameter $(/ \mathbf{m m})$} \\
\cline { 2 - 4 } & $\mathbf{2 0}$ & $\mathbf{2 2}$ & $\mathbf{2 5}$ \\
\hline$L=8 d$ & 2.05 & 1.92 & 1.63 \\
$L=10 d$ & 3.17 & 3.38 & 2.85 \\
$L=12.5 d$ & 4.08 & 3.55 & 3.77 \\
\hline
\end{tabular}

The American standard ACl-318 (American Concrete Institute, 1999) and British standard BS8110 (BS, 1997) stipulate that the displacement ductility coefficient $\left(R_{d}=\delta_{u} / \delta_{y}\right)$ of the connector should be greater than 4 . In this test, when $\mathrm{L} / \mathrm{d}$ was 12.5 , the ductility coefficient of the specimen was close to 4 , which basically met these two requirements. The diameter of the steel bar had no obvious effect on the ductility of the specimen. 


\section{REINFORCEMENT AND SLEEVE STRAIN}

\subsection{Longitudinal strain of sleeve}

The longitudinal strain of the sleeve is caused by two forces. The axial force of the sleeve is formed by the shear stress caused by the bonding force of the steel bar, which is the force analyzed above; there is also the force caused by the expansion of the grout. The expansion of the grouting material causes the sleeve to be squeezed. Due to the Poisson's ratio effect, the sleeve is subjected to longitudinal force, which accounts for a small proportion of the forces of the sleeve.

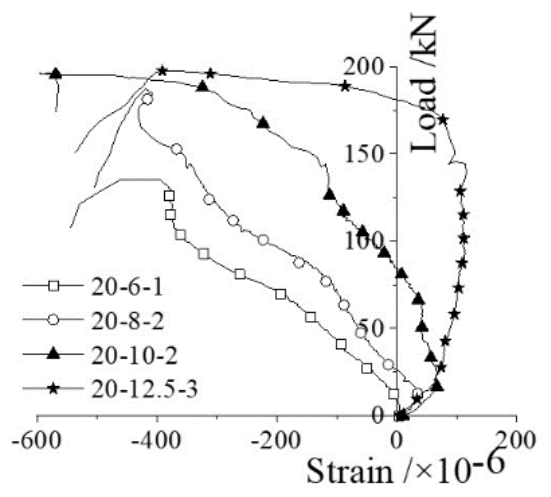

(a) $d=20 \mathrm{~mm}$ (SG9)

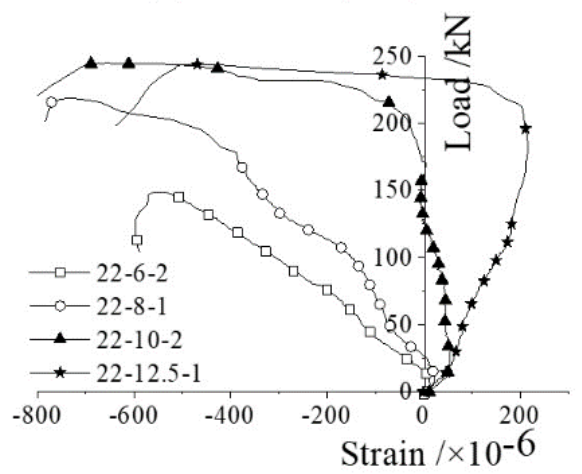

(c) $d=22 \mathrm{~mm}$ (SG9)

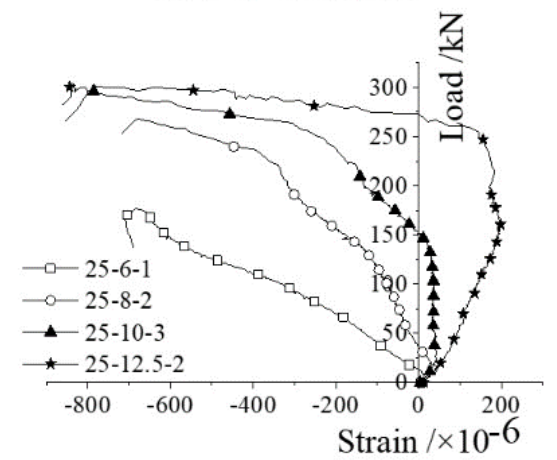

(e) $d=25 \mathrm{~mm}$ (SG9)

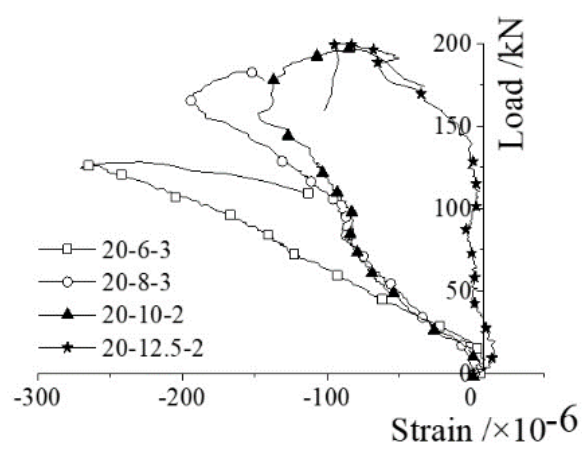

(b) $d=20 \mathrm{~mm}$ (SG10)

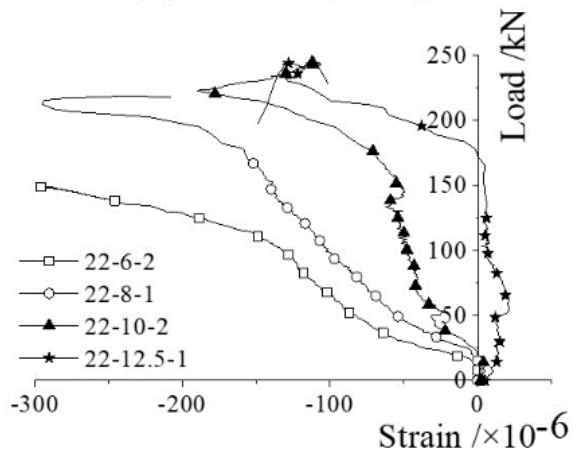

(d) $d=22 \mathrm{~mm}(S G 10)$

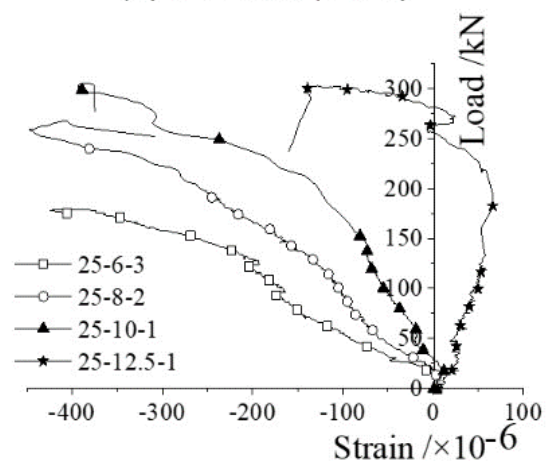

(f) $d=25 \mathrm{~mm}(S G 10)$

Figure 13 Typical load-longitudinal strain curve of the one-half length section of sleeve

Figure 13 shows the load-strain curves of typical longitudinal strains of SG9 and SG10 on the near and far steel bar side of the half-length section of the sleeve. Tensile strain in the early stage of loading gradually changes to compressive strain as the load increases. The tensile-compression transition load of the sleeve longitudinal strain gradually increases with the lap length. For specific analysis, see Section 5.2.

Figure 14 shows the influence of the relative lap length on the maximum longitudinal tensile strain of the half-length section of the sleeve. The maximum longitudinal tensile force of the sleeve appears between the beginning of the load and the transition load between tension and compression. The longitudinal tensile strain of SG9 of the sleeve on the near steel bar side increases with the lap length, while the law of the longitudinal tensile strain of SG10 of the sleeve on the far steel bar side is not obvious. 


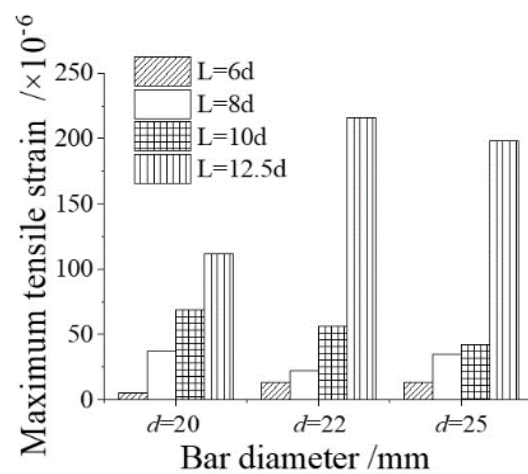

(a) SG9

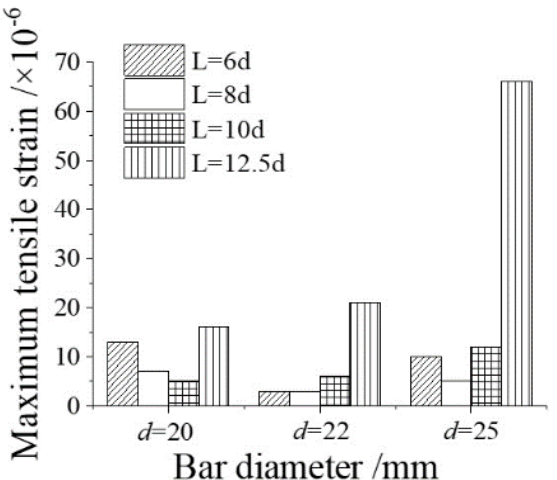

(b) SG10

Figure 14 Typical load-longitudinal strain curve of the middle section of sleeve

Figure 15 shows the influence of the relative lap length on the extreme values of the longitudinal compressive strains of SG9 and SG10 of the sleeve on the near and far steel sides of the half-length section under ultimate load. The longitudinal compressive strain of SG10 of the sleeve on the far steel bar side decreases with the increase of the lap length, and the longitudinal compressive strain of SG9 of the sleeve near the steel bar has no obvious correlation with the relative lap length.

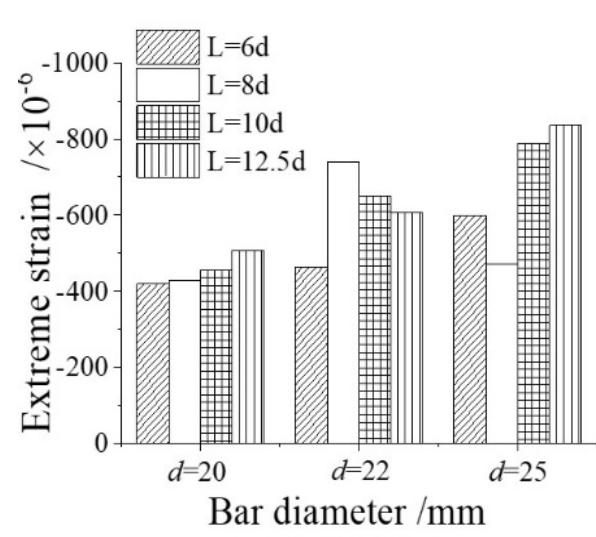

(a) SG9

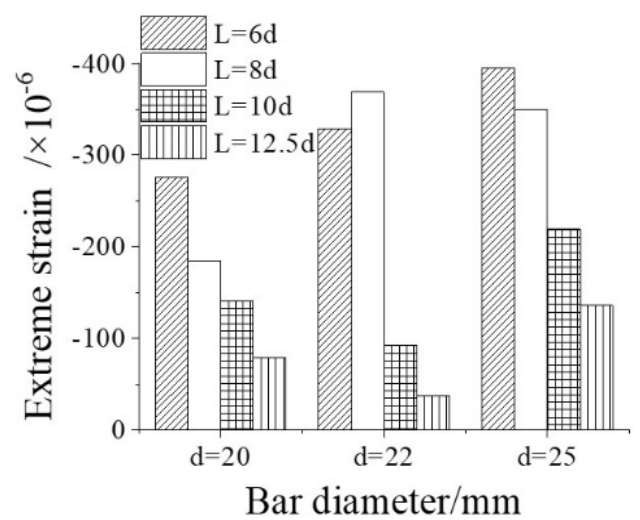

(b) SG10

Figure 15 Effect of relative lapping length on the extreme longitudinal stress strain of one-half section under limit load

With the increase of the lap length, the tensile-compression conversion load of the sleeve increases; the more fully the sleeve tension develops, the greater the sleeve tension and tensile strain. When the lap length is large, the steel bar is generally broken and damaged, and the compression stage of the specimen is short; so, the ultimate compressive strain is also small. This is the general law of the development of the longitudinal strain in the middle of the sleeve as the lap length changes. As the lap length increases, at the beginning of loading, the longitudinal tensile strain of the sleeve near the steel bar (SG9) is large, and this law is more obvious, while the tensile strain of the far steel bar side is small, and the law is not obvious. Under the ultimate load, the longitudinal compressive strain of the sleeve on the far side of the steel bar (SG10) becomes smaller. This law is more obvious, but the law is not obvious when the side of the near steel bar (SG9) is affected by the compressive strain caused by deflection.

Figure 16 shows the comparison of the longitudinal load-strain curves of the sleeves on the near and far sides of the rebar in typical half-, one-third-, and one-sixth-length sections when the lap length is $12.5 \mathrm{~d}$. In the early stage of loading, the tensile force on the sleeve near the steel bar is greater than that on the sleeve on the far steel bar side (in Figure 16(c), one-sixth of the length of the sleeve is compressed at the early stage of loading due to the deflection of the specimen). In the later stage of loading, the longitudinal pressure of the sleeve near the steel bar is greater than that of the far steel bar. This means that during the whole loading process, the strain on the side of the rebar near the sleeve is greater than that on the side of the far rebar. In the test, the tensile strain value of the sleeve under longitudinal tension was small, and the compressive stress under longitudinal compression was slightly larger, but none exceeded the yield strain of the steel, indicating that the sleeve is always in an elastic working state. 


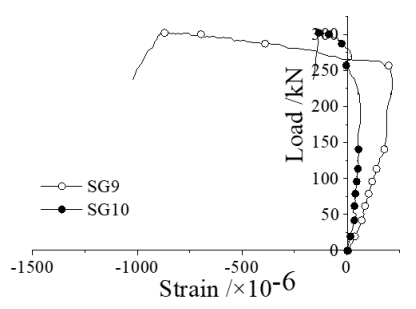

(a) One-half section

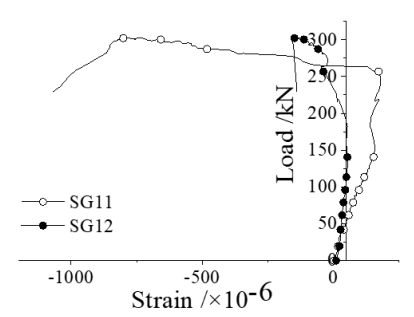

(b) One-third section

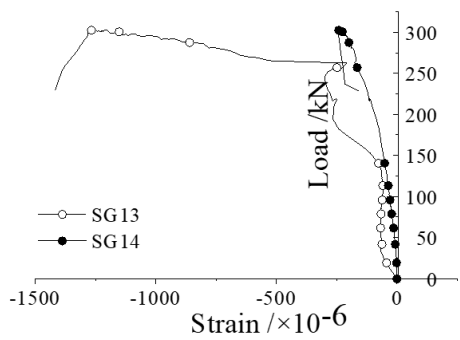

(c) One-sixth section

Figure 16 Load-longitudinal strain curve of sleeve of 25-12.5-1 specimen

\subsection{Circumferential strain of sleeve}

\subsubsection{Half-length section of sleeve}

Figure 17 shows the load-strain curves of the circumferential strains of SG5 and SG6 of the near and far steel bars in the half-length section of the sleeve.

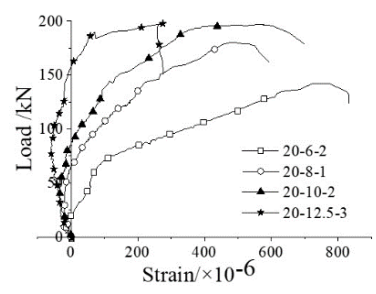

(a) $d=20 \mathrm{~mm}$ (SG5)

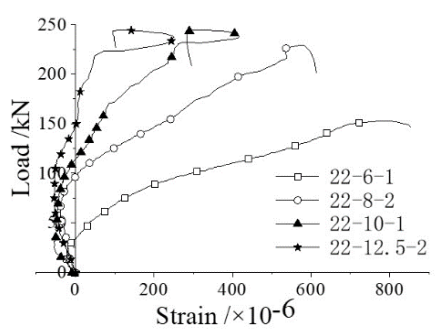

(c) $d=22 \mathrm{~mm}$ (SG5)

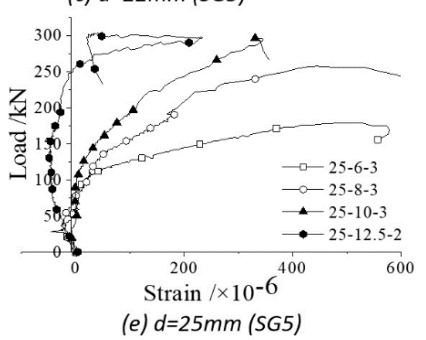

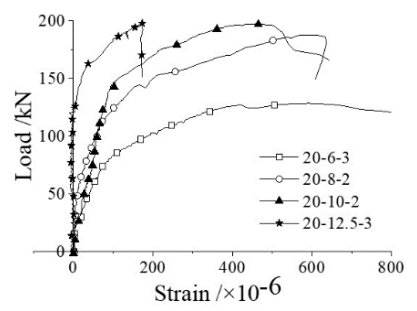

(b) $d=20 \mathrm{~mm}$ (SG6)

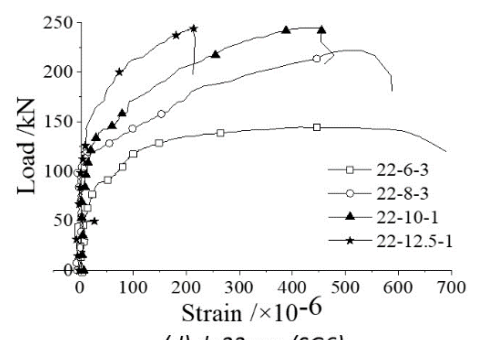

(d) $d=22 \mathrm{~mm}$ (SG6)

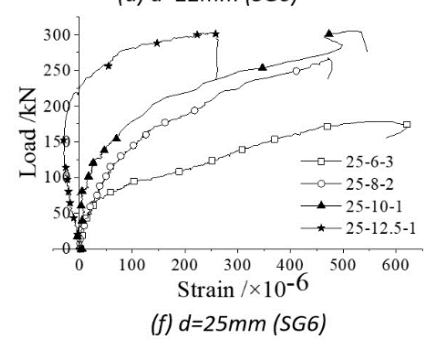

Figure 17 Load-circumferential strain curve of the one-half length section of sleeve 
The circumferential strain of the sleeve is also caused by two forces. One is the expansion of the grouting material, which causes the sleeve to be pulled in the circumferential direction. Also, due to the Poisson's ratio effect, hoop stress appears in the sleeve, and this accounts for a small force.

At the beginning of loading, the circumferential strain of SG5 near the steel bar of the half-length section of the sleeve is mainly controlled by the longitudinal stress of the sleeve. As the entire sleeve is stretched longitudinally, the sleeve shrinks radially under the influence of the Poisson's ratio effect, which then manifests as compressive strain. During the loading process, the expansion of the grouting material gradually plays a controlling role, and the ring direction of the sleeve changes to tensile strain. For a given steel bar diameter, the greater the lap length of the specimen, the more obvious the sleeve ring compression and the greater the compression-tension transition load. This is because the larger the lap length, the smaller the average bonding force and the smaller the hoop expansion; so, hoop compressive strain lasts longer, hoop tensile strain appears later, and the compression-tension transition load increases.

The load-strain curve on the far side of the steel bar with a half-length section of the sleeve changes with the lap length, similar to that on the near side. The curves on the near and far sides of the bar with a diameter of $25 \mathrm{~mm}$ have the highest similarity (i.e., the anchoring length is $12.5 \mathrm{~d}$, the $25-\mathrm{mm}$ diameter steel bar has an obvious compression section in the early stage of loading, and the compression section of the remaining specimens is not obvious). This is because the larger the diameter of the steel bar, the closer the steel bars are to the inner wall of the sleeve and so the less impact of the far side steel bar on the sleeve.

\subsubsection{Edge section of sleeve}

Figure 18 shows the load-strain curves of the circumferential strains of SG7 and SG8 on the side of the near and far steel bars at the edge of the specimen sleeve. During the entire loading process, the circumferential strain of the sleeve edge section is all tensile strain.

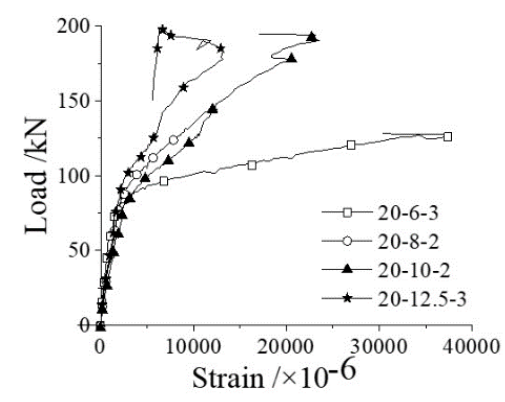

(a) $d=20 \mathrm{~mm}(S G 7)$

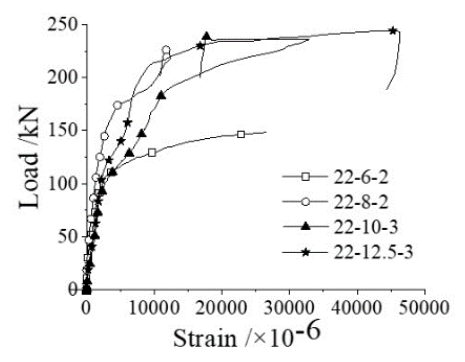

(c) $d=22 \mathrm{~mm}$ (SG7)

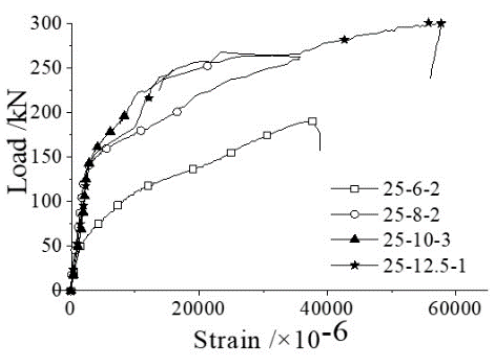

(e) $d=25 \mathrm{~mm}$ (SG7)

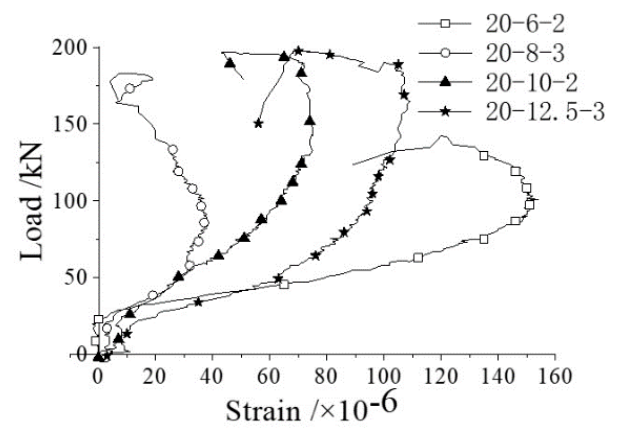

(b) $d=20 \mathrm{~mm}$ (SG8)

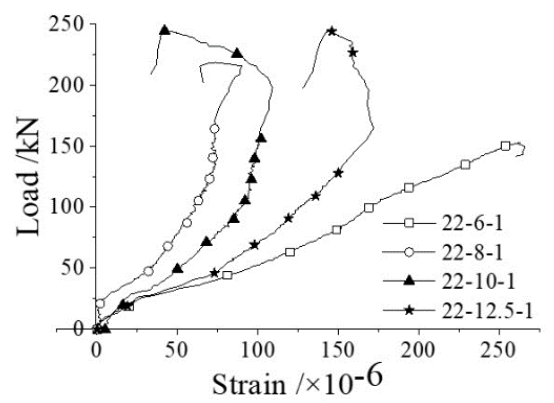

(d) $d=22 \mathrm{~mm}(S G 8)$

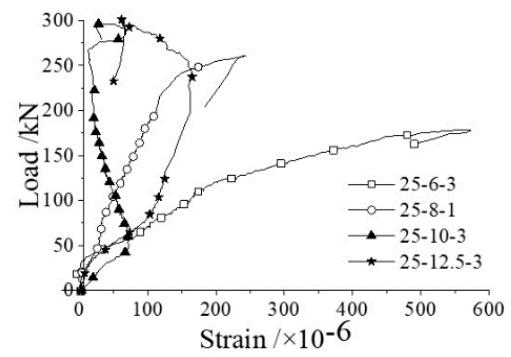

(f) $d=25 \mathrm{~mm}$ (SG8)

Figure 18 Load-circumferential strain curve of the edge section of sleeve 
Before the circumferential strain (SG7) on the side near the steel bar reaches the yield strain of the steel, the load-strain curves with the same steel bar diameter almost overlap and are basically straight lines. After the sleeve hoop yields, the loadstrain curve of the specimen has a significant turn, and the sleeve strain increases sharply. However, because this hoop yielding occurs in a local area, the load-bearing capacity of the specimen continues to increase. When the specimen was damaged, the sleeve strain was very large, and some of the strain gauges on the specimen were damaged. However, since the deformation did not exceed the actual ultimate tensile strain of the sleeve base material, no fracture of the sleeve was observed.

The circumferential strain (SG8) on the far side of the steel bar is relatively small, which does not exceed the yield strength of the base material of the sleeve, and the sleeve is in an elastic working state.

\subsubsection{Comparison of circumferential strain of half-length and end sections of sleeve on far side of steel bar}

Figure 19 shows the typical load-strain curves of the half-length section (SG6) and end section (SG8) of the sleeve on the far steel bar side. Generally, in the early stage of loading, the circumferential tensile strain of the edge section develops faster than that of the half-length section. Under the same load, the circumferential tensile strain of the edge section is greater than that of the half-length section. However, as the load increases, the strain of the edge section begins to develop in the opposite direction, i.e., when the load increases, the circumferential strain of the sleeve edge section decreases, which indicates that the grouting material on the edge section begins to exhibit micro-cracks and damage. With the increase of load, the strain of SG8 in the circumferential direction of the far steel bar further decreases, and finally, the strain of SG8 is much smaller than that of SG6.
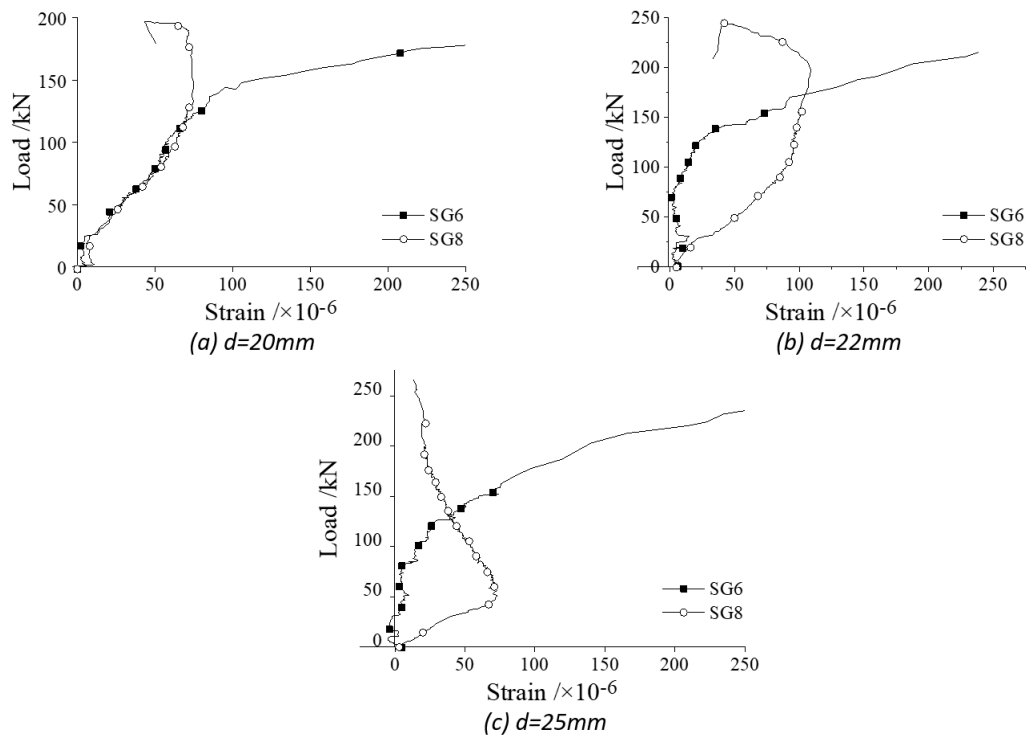

Figure 19 Typical curve of SG6 and SG8(Specimens with lapping length of 10d)

Figure 20 shows the comparison of the average value of the circumferential strain on the side of the outer steel bar from the half-length section of the sleeve and the edge section when the specimen is under a load of $75 \mathrm{kN}$ and the maximum bearing capacity. Under a load of $75 \mathrm{kN}$, the circumferential strain of SG6 of the half-length section of the far steel bar side of the specimen is smaller than the circumferential strain of SG8 of the edge section. Under the ultimate load, the circumferential strain of SG6 of the half-length section of the far steel bar side of the specimen is much larger than that of SG8 of the edge section. See Section 5.2 for analysis.

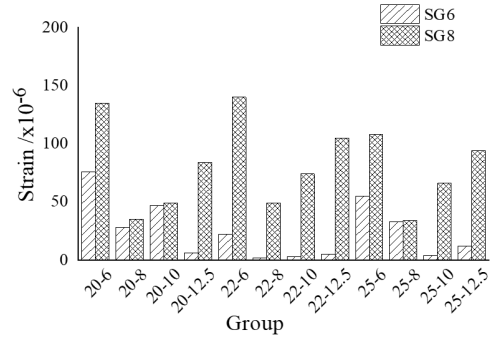

(a) $75 \mathrm{kN}$

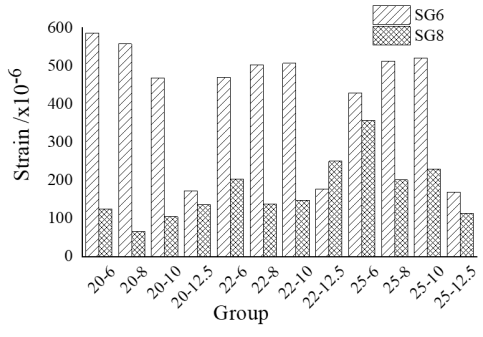

(b) ultimate load

Figure 20. Comparison of average values of SG6 and SG8 under $75 \mathrm{kN}$ and ultimate load 


\subsection{Longitudinal strain of steel bar}

Figure 21 shows the typical load-strain curve of the inserted steel bar (SG1) and reserved steel bar (SG2) outside the sleeve (the strain is not much different before yielding). The strain curve of the steel bar outside the sleeve shows a certain yield stage, which is shorter than that of the steel bar.

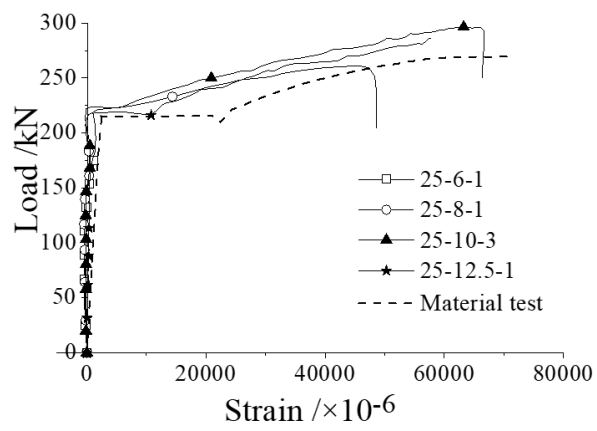

(a) $d=25 \mathrm{~mm}$ (SG1)

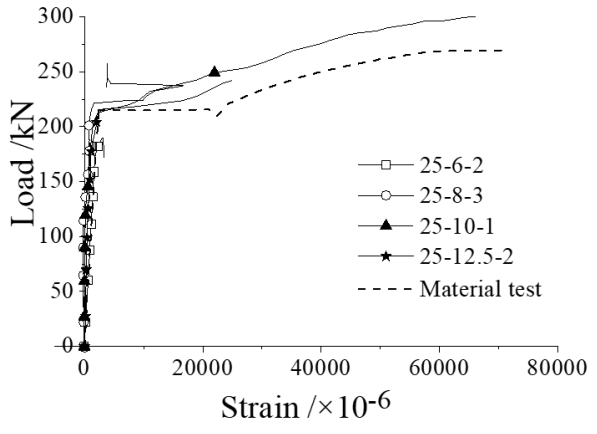

(b) $d=25 \mathrm{~mm}(S G 2)$

Figure 21 Typical load-strain curve of bar outside the sleeve

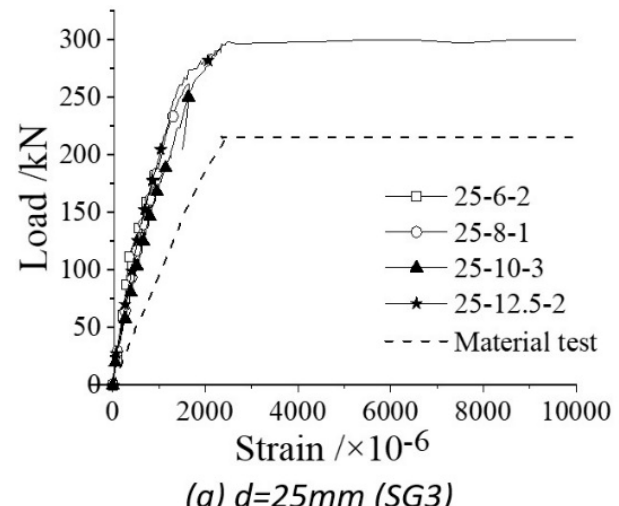

(a) $d=25 \mathrm{~mm}(\mathrm{SG} 3)$

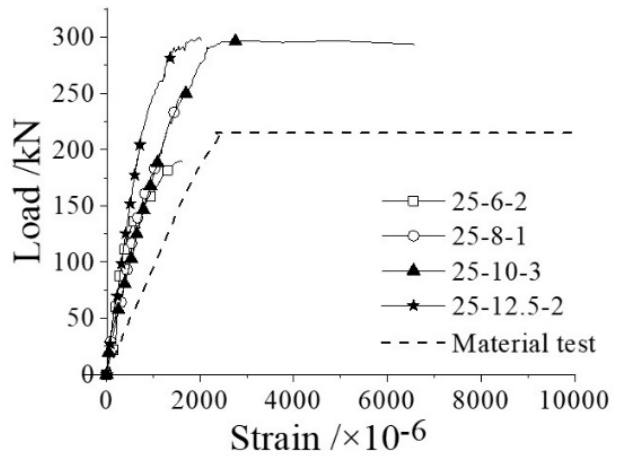

(b) $d=25 \mathrm{~mm}$ (SG4)

Figure 22 Typical load- strain curve of bar at the one-half length of connector

Figure 22 shows the typical load-strain curves of steel bars inserted inside the sleeve and reserved steel strain measuring points SG3 and SG4. Because part of the load transferred from the external steel bar to the connector is through the interaction between the steel bar and the grouting material, under the same load, the strain of the internal steel bar is less than that of the steel bar property test. In addition, the yielding platform of the steel bar property test is long $\left(2 \times 10^{3}-2 \times 10^{4}\right)$. The properties of the steel bars in the figure are only part of the curve, and there is no strengthening stage of the steel bars; so, they have not yet entered the strengthening stage when the specimen reaches the ultimate bearing capacity.

\section{WORKING MECHANISM OF CONNECTOR UNDER TENSION AND ANALYSIS OF SLEEVE BONDING FORCE}

\subsection{Working mechanism of grouted splice connector}

Figure 23 shows the schematic diagram of the force transmission of the grouted splice connector. Under the action of tension, the force of the steel bar, sleeve, and grouting material in the grouted splice connector is shown in Figure 24(a)-(c), respectively. The load transfer between the two steel bars is realized by the bonding force between the grouting material and the steel bar and the sleeve. From the axial point of view, the sleeve is symmetric about the symmetry axis in the middle, and one side is used for analysis. As shown in Figure 24(d) and Figure (e), the stress transmission in the middle of the sleeve is mainly realized by the tension of the sleeve and the grout. Therefore, the force transmission path is long and not direct enough, and the tensile strength of the grouting material is lower than that of the steel bar, which is not good for the connector. 


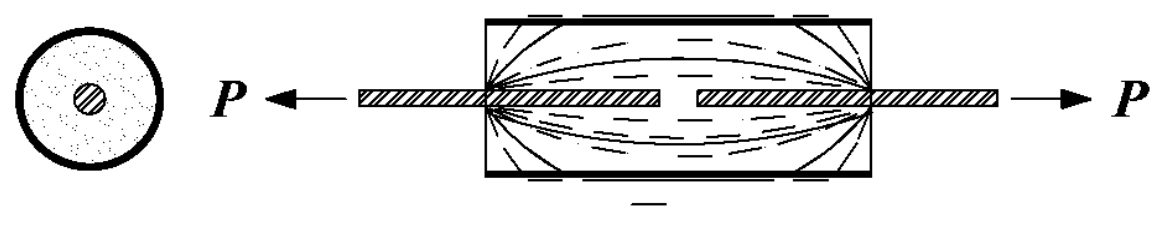

Figure 23 Load condition of grouted splice connection

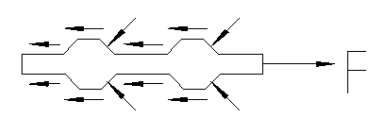

(a) Force of steel bars in grouted splice connection

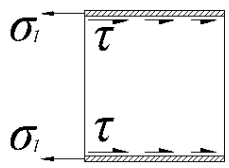

(d) Force of half sleeve

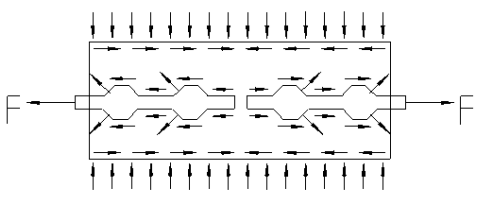

(b) Force of grouting material in grouted splice connection

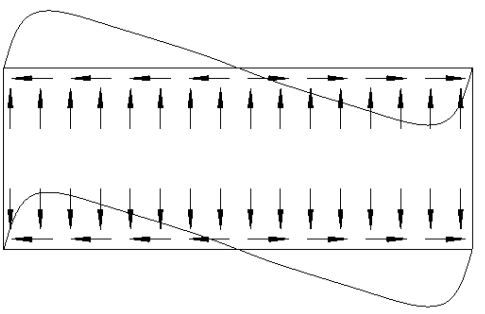

(c) Force of sleeve

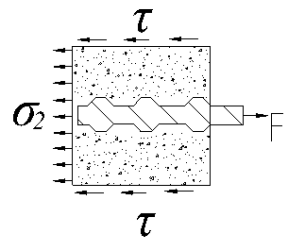

(e) Force of half grout in the sleeve

Figure $\mathbf{2 4}$ Load condition of grouted splice connection

In this connector, the sleeve is mainly under tension; thus, the sleeve's tensile bearing capacity should at least be greater than that of the connected steel bars. The two steel bars have a limited area of action on the sleeve and grouting material. Their effects are barely superimposed; thus, the working mechanism of the connector is relatively simple.

\subsection{Working mechanism of grouted sleeve lapping connector}

Figure 25 shows the force transmission diagram of the grouted sleeve lapping connector. Figure 26 shows the diagram of the force transmission between the ribs when the two steel bars are not close together under the sleeve constraint. When the connector is tensioned, the forces of the two steel bars are opposite, and they are ribbed and constrained in the sleeve. The effect on the grouting material is shown in Figure 26(a). There is shear stress $\tau$ and oblique compression stress $\sigma$. The force of the inclined limb of the intercostal grouting material is shown in Figure 26(b). As shown in Figure 26(c), $\sigma$ is decomposed into $\tau^{\prime}$ and $\sigma^{\prime} ; \sigma^{\prime}$ causes the grouting material around the steel bar to expand radially, and $\tau^{\prime}$ is the shear stress, which in turn generates $\sigma_{z}$, which causes the inclined limb to be pulled. As shown in Figure 26(d), $\sigma_{z}$ causes tearing cracks in the inclined limb, and the separation trend of the steel bars caused by the reaction force $\sigma$ ' of the grout to the steel bars is shown in Figure 26(e) and Figure (f).

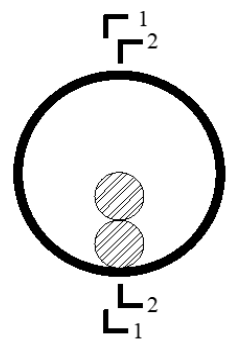

(a) Cross section

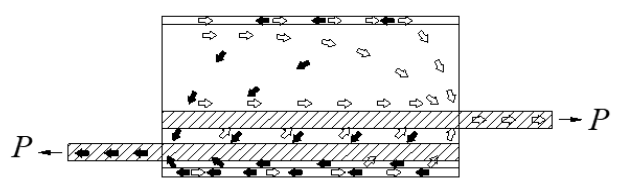

(b) Section 1-1

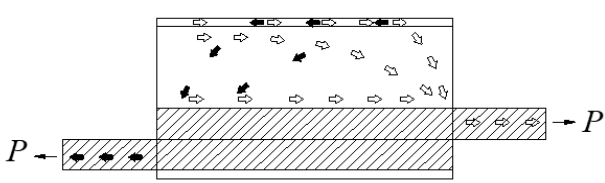

(c) Section 2-2

Figure $\mathbf{2 5}$ Load condition of grouted lapping connection 


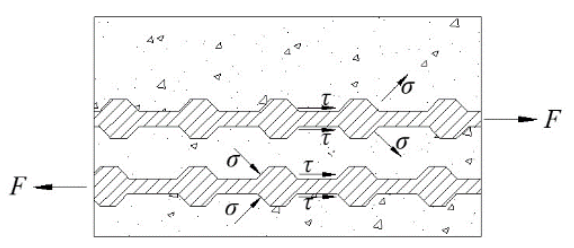

(a) The effect of steel bars on grouting

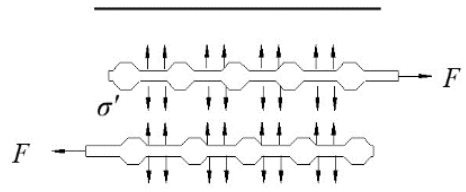

(c) Radial expansion of grouting around steel bars

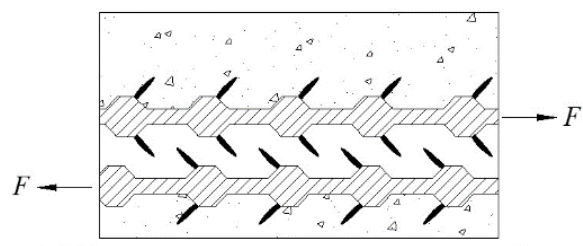

(e) Tearing cracks caused by main tensile stress

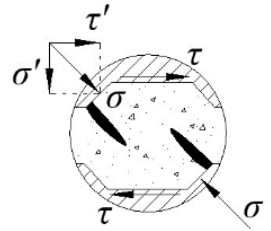

(b) Force of the oblique limb of the intercostal grout

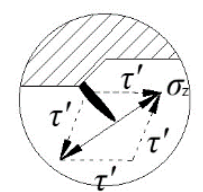

(d) Principal tensile stress generated by the grouting material at the rib end

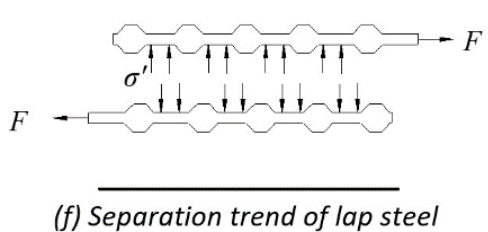

(f) Separation trend of lap steel

Figure 26 Load condition of grouted lapping connection

Since the forces of the two steel bars on the sleeve are opposite, their force on the sleeve is mostly offset, and the role of the sleeve is to restrain the expansion of the grout caused by the two steel bars. So, it is a strong restraint on the grouting material.

\subsection{Analysis of bonding force on inner wall of sleeve}

Xu (1990) measured the long- and short-anchored specimens by the pull-out test. The distribution of the bonding force between the steel bar and the concrete along the anchoring length varies with the load, as shown in Figure 27(a) and Figure (b). The development of the bonding force during loading is the process in which its maximum along the longitudinal direction of the steel bar changes from the loading end to the free end at each stage.

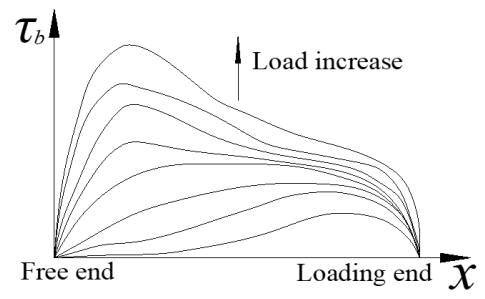

(a) Bonding force distribution of long anchor specimen

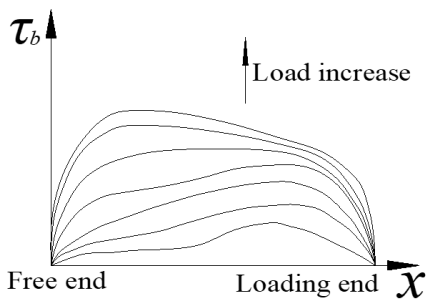

(b) Bonding force distribution of short anchor specimen

Figure 27 Distribution of bar-concrete bonding strength along anchorage length

Figure 28(a) shows the distribution of the bonding force $\tau_{b}$ between the two steel bars and the grouting material within the lap length range at the initial stage of loading (Walker et al., 1997). When the load is close to the ultimate load, the distribution of $\tau_{b}$ is as shown in Figure 30(a).

The effect of the sleeve wall in the longitudinal direction of the sleeve is the superposition of the bonding force between the two steel bars and that which is transferred to the barrel wall through the grouting material. The forces of the two steel bars are in opposite directions. The grouting material has the opposite effect on the sleeve wall; the two forces cancel each other, reducing the axial force on the sleeve.

The factors affecting the longitudinal force of the sleeve are: (1) the size and direction of the bonding force between the steel bar and the grouting material; and (2) the distance between the point on the sleeve and the steel bar; the closer the distance, the greater the force on the sleeve. 
The bonding force of the two steel bars is antisymmetric along the length direction. At the half-length section of the sleeve, the bonding forces between the two steel bars and the grouting material are equal and opposite ( $\tau_{1}$ is equal to $\tau_{2}$ in Figure 28(a) and Figure 30(a)). On the wall of the barrel at the half-length of the sleeve, the bonding force to points $A$ and $A^{\prime}$ at the same distance between the two steel bars is zero. Figure 29 shows the bonding force distribution on the half-length of the sleeve, where ' $\bullet$ ' indicates that the direction is perpendicular to the plane outward, ' $x$ ' indicates that the direction is perpendicular to the plane inward, and the size of the symbol mentioned above in the figures indicates the size of the adhesive force. The bonding forces on points $B$ and $C$ on the sleeve are in opposite directions.

At the initial stage of loading, due to the uneven distribution of the bonding force between the steel bar and the grouting material, as shown in Figure 28(a), the bonding force is large near the tensile end of the two steel bars and almost zero near the free end of the inserted steel bar.

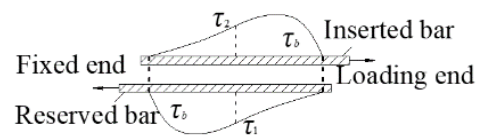

(a) Bonding force distribution of steel bars at the beginning of loading

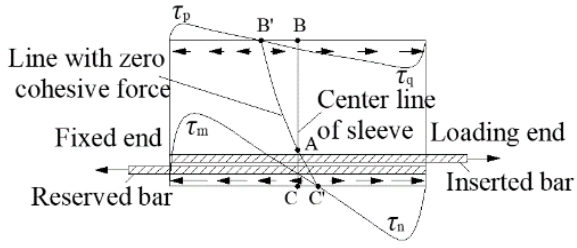

(b) Bonding force on the sleeve

Figure 28 Bonding force

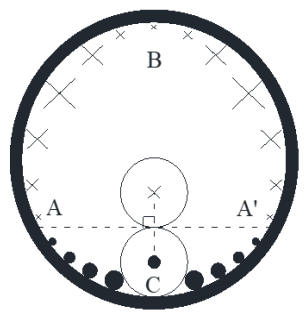

Figure 29 Distribution of the longitudinal bonding force between the sleeve and the grouting material at half the length
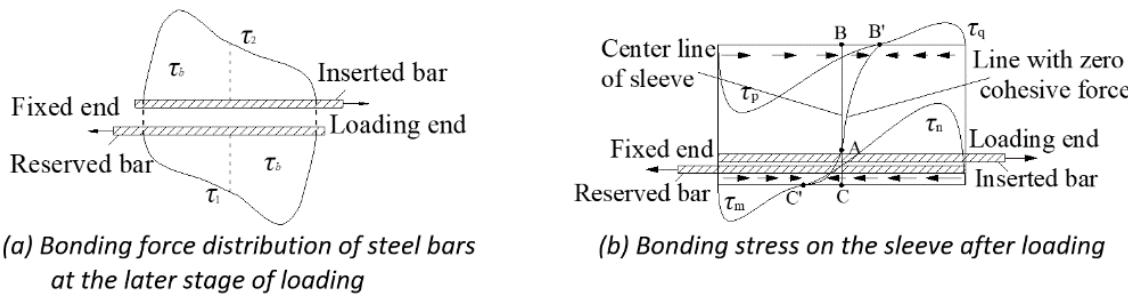

(b) Bonding stress on the sleeve after loading

Figure 30 Sleeve-grout bonding force in the ultimate loading stage

At the loading end of the specimen, since the bonding force of the inserted steel bar is much greater than that of the reserved steel bar, the size and direction of the bonding force on the sleeve on this section are determined by the inserted steel bar. The closer the distance between the sleeve and the inserted steel bar, the greater the bond strength.

The force on the fixed end of the specimen is opposite to the loading end, and the bonding force on the sleeve on the fixed end section is mainly determined by the reserved steel bar.

As shown in Figure 29, the bonding force at point B on the sleeve on the far side of the steel bar at the half-length section is consistent with the direction of the force on the inserted steel bar. The force direction of point $\mathrm{C}$ on the side near the steel bar is consistent with the force direction of the reserved steel bar. The adhesive force on the sleeve is shown in Figure 28(b). Point $C^{\prime}$, on the side of the near steel bar with zero bonding force, is biased to the side of the loading end, and point B', at the far side of the steel bar with zero bonding force, is biased to the side of the fixed end. It can be seen that during the initial loading of the sleeve, the sleeve is axially pulled. In the early stage of loading, the maximum longitudinal tensile strain on the side of the near and far steel bars at the half-length section of the sleeve is 
as presented in Table 6 . It can be seen that the theoretical analysis is consistent with the experimental results, and the maximum longitudinal tensile strain of the sleeve is $295 \times 10^{-6}$, which is very small.

When loaded to the limit state, assuming no damage to the grouting material, the bonding force distribution between the steel bar and the grouting material is as shown in Figure 30(a). Similar to the analysis at the initial stage of loading, it can be seen that under the ultimate load condition, the bonding stress on the far and near steel side sleeves at the fixed end is consistent with the force direction of the inserted steel bars. The bonding stress of the far and near steel side sleeves at the loading end is consistent with the force direction of the reserved steel bars. It can be seen from Figure 29 that the bonding stress of the sleeve on the far side of the steel bar at the half-length section is consistent with the direction of the force of the inserted steel bar, and the direction of the force on the side of the near steel bar is the same as that of the reserved steel bar. Figure 30(b) shows the bonding stress on the sleeve of the specimen under the ultimate load, drawn according to the above analysis. It can be seen that the direction of the bonding stress of the grouting material to the sleeves on the far and near steel bars in the later stage of loading is opposite. As a result, the sleeve is under pressure in the axial direction. When the half-length section of the sleeve is under the ultimate load, the longitudinal compressive strains of the near and far steel bars are as presented in Table 6, which shows that the theoretical analysis is consistent with the test results. The maximum longitudinal compressive strain of the steel bar for the specimen, whose failure pattern is steel bar fracture, is $1021 \times 10^{-6}$, which shows that the strain is very small.

Table 6 Longitudinal sleeve strain of the near and far side at $1 / 2$ section

\begin{tabular}{|c|c|c|c|c|c|}
\hline \multirow{2}{*}{ Specimen } & \multirow{2}{*}{ Failure pattern } & \multicolumn{2}{|c|}{ Strain near the bar side $\left(\times 10^{-6}\right)$} & \multicolumn{2}{|c|}{ Strain far from the bar side $\left(\times 10^{-6}\right)$} \\
\hline & & Preload & Ultimate load & Preload & Ultimate load \\
\hline $20-6-1$ & steel bar pulled out & 5 & -529 & 2 & -300 \\
\hline $20-6-2$ & steel bar pulled out & 5 & -320 & 5 & -309 \\
\hline $20-6-3$ & steel bar pulled out & 5 & -837 & 4 & -270 \\
\hline $22-6-1$ & steel bar pulled out & 5 & -702 & 4 & -391 \\
\hline $22-6-2$ & steel bar pulled out & 6 & -597 & 3 & -296 \\
\hline $22-6-3$ & steel bar pulled out & 13 & -292 & 4 & -345 \\
\hline $25-6-1$ & steel bar pulled out & 13 & -705 & 7 & -225 \\
\hline $25-6-2$ & steel bar pulled out & 6 & -791 & 3 & -406 \\
\hline $25-6-3$ & steel bar pulled out & 6 & -440 & 10 & -424 \\
\hline $20-8-1$ & steel bar pulled out & 21 & -486 & 4 & -228 \\
\hline $20-8-2$ & steel bar pulled out & 37 & -504 & 7 & -200 \\
\hline $20-8-3$ & steel bar pulled out & 24 & -619 & 7 & -194 \\
\hline $22-8-1$ & steel bar pulled out & 22 & -953 & 3 & -295 \\
\hline $22-8-2$ & steel bar pulled out & 33 & -761 & 5 & -467 \\
\hline $22-8-3$ & steel bar pulled out & 64 & -964 & 3 & -416 \\
\hline $25-8-2$ & steel bar pulled out & 35 & -784 & 5 & -448 \\
\hline $25-8-3$ & steel bar pulled out & 30 & -748 & 15 & -403 \\
\hline $20-10-1$ & Steel bar break & 35 & -936 & 5 & -233 \\
\hline $20-10-2$ & steel bar pulled out & 30 & -1045 & 11 & -140 \\
\hline $20-10-3$ & steel bar pulled out & 69 & -638 & 4 & -234 \\
\hline $22-10-1$ & Steel bar break & 56 & -713 & 10 & -101 \\
\hline $22-10-2$ & steel bar pulled out & 103 & -2459 & 5 & -190 \\
\hline $22-10-3$ & steel bar pulled out & 65 & -1103 & 16 & -166 \\
\hline $25-10-1$ & steel bar pulled out & 47 & -1030 & 12 & -486 \\
\hline $25-10-3$ & steel bar pulled out & 42 & -959 & 32 & -263 \\
\hline $20-12.5-1$ & Steel bar break & 295 & -818 & 5 & -127 \\
\hline $20-12.5-2$ & Steel bar break & 116 & -602 & 16 & -102 \\
\hline $20-12.5-3$ & Steel bar break & 142 & -537 & 14 & -55 \\
\hline $22-12.5-1$ & Steel bar break & 216 & -695 & 17 & -146 \\
\hline $22-12.5-2$ & Steel bar break & 146 & -895 & 24 & -33 \\
\hline $22-12.5-3$ & Steel bar break & 125 & -790 & 40 & -112 \\
\hline $25-12.5-1$ & Steel bar break & 219 & -1021 & 66 & -160 \\
\hline $25-12.5-3$ & Steel bar break & 160 & -961 & 97 & -178 \\
\hline
\end{tabular}


It can be seen from Table 6 that the strain of the sleeve is very small during the loading process; so, the sleeve has low requirements for material performance, and no internal treatment is required. The requirements for the tensile performance of the grouting material are relatively low, which can be C60, and the sleeve diameter is large. The maximum particle size of the grouting material can be controlled within $4.75 \mathrm{~mm}$, which makes the cost of the connector relatively low. In the early stage of loading, the longitudinal tensile strain of the sleeve near the steel bar is greater than that of the far steel bar, and the longitudinal compressive strain of the sleeve near steel bar is also greater than the compressive strain of the far away steel bar during the ultimate load, i.e., the force of the sleeve near the steel bar is greater than that of the far steel bar side, which is consistent with the viewpoint in the analysis that the closer the distance between the steel bars, the greater the force on the sleeve.

The change process of the bonding force of the steel bar in the grouting is such that the maximum bonding force on its surface develops from the loading end to the free end. As shown in Figure 27, the longer the lap length, the longer the bonding force path of the steel bar, and the slower the development of the maximum bonding force to the free end, that is, the slower the transition from the state shown in Figure 28(a) to that shown in Figure 30(a) at the initial stage of loading, the greater the sleeve longitudinal tensile-compression transition load.

At the beginning of loading, the circumferential strain of the edge section of the sleeve is greater than that of the middle section. Table 7 lists the strain and the resultant force of the two steel bars inside the half-length section of the sleeve under a load of $75 \mathrm{kN}$. F=As $\times \mathrm{Es} \times \varepsilon_{\mathrm{SG}}$, where As is the cross-sectional area of the steel bar; Es is the elastic modulus, taken as $2.06 \times 10^{5} \mathrm{MPa}$; and $\varepsilon_{\mathrm{SG}}$ is the cross-sectional strain of the steel bar in the middle of the sleeve. It can be seen that the total force of the steel bars in the middle section of the sleeve is less than the external load of $75 \mathrm{kN}$, indicating that the force of one steel bar in the edge section of the specimen is greater than the sum of the internal forces of the two steel bars in the middle section. According to Figure 26(c), the circumferential strain of the sleeve is formed by the radial expansion force generated by the steel bars; so, the circumferential expansion force of the edge section is greater than that of the middle section, i.e., SG8 is greater than SG6. Under the ultimate load, the grouting material on the far side of the steel bar at the end of the sleeve falls off greatly, and the circumferential tensile force of the sleeve drops rapidly; so, the circumferential strain SG6 in the middle section is greater than that at the edge section of SG8.

Table 7 Resultant force of internal reinforcement at $1 / 2$ section under $75 \mathrm{KN}$ load

\begin{tabular}{|c|c|c|c|c|c|}
\hline \multirow{2}{*}{$\begin{array}{l}\text { Diameter of Steel bar } \\
(\mathbf{m m})\end{array}$} & \multicolumn{2}{|c|}{ SG3 } & \multicolumn{2}{|c|}{ SG4 } & \multirow{2}{*}{ Total force of the steel bar $/ \mathrm{kN}$} \\
\hline & Strain $/ 10^{-6}$ & $\mathrm{~F} / \mathrm{kN}$ & Strain $/ 10^{-6}$ & $\mathrm{~F} / \mathrm{kN}$ & \\
\hline 20 & 527 & 34.1 & 377 & 24.4 & 58.5 \\
\hline 22 & 419 & 32.8 & 393 & 30.8 & 63.6 \\
\hline 25 & 359 & 36.3 & 281 & 28.4 & 64.7 \\
\hline
\end{tabular}

\section{CALCULATION OF ULTIMATE BOND STRENGTH AND CRITICAL LAP LENGTH}

\subsection{Ultimate bond strength}

Xu conducted a lap tensile test of spiral steel bars (Xu et al., 1993), which showed that the factors affecting their lap strength are concrete strength, protective layer thickness, hoop ratio, and lap length. According to the test, the ultimate strength of the steel bar lap is obtained as follows:

$\bar{\tau}_{u}=\left(0.7+2.5 \frac{d}{l}\right)\left(0.5+0.6 \frac{c}{d}+55 \rho_{s v}\right) f_{t}$

where $\mathrm{I}$ is the lap length, $\mathrm{c}$ is the thickness of the concrete protective layer, $\rho_{\mathrm{sv}}$ is the hoop ratio, and $\mathrm{f}_{\mathrm{t}}$ is the concrete tensile strength.

If the sleeve is regarded as a matching hoop, it can be obtained by analyzing the specimen whose failure mode is the steel bar pull-out in this test, and the bonding strength of the steel bar in the specimen is positively correlated with the grouting strength $\mathrm{fts}$, relative sleeve thickness $\mathrm{D} / \mathrm{d}$, reciprocal of the relative overlap length $\mathrm{d} / \mathrm{L}$, and hoop ratio $\rho s \mathrm{v}$, calculated for the middle sleeve as follows:

$\rho_{s v}=\frac{\pi\left[(D+2 t)^{2}-D^{2}\right]}{\pi D^{2}} \approx \frac{t(D+t)}{D^{2}} \approx \frac{t}{D}$

The test value of the average ultimate bonding force of the specimen is 


$$
\tau_{u e}=\frac{P_{u}}{\pi d L}
$$

The equation for the ultimate bond strength of the grouted sleeve lapping connector obtained by fitting the test data in this paper and the relevant test data in the previous period is

$\tau_{u}=\left(0.69+1.05 \frac{d}{L}\right)\left(5.89-0.27 \frac{D}{d}+5.84 \frac{t}{D}\right) f_{\mathrm{ts}}$

Where $\tau_{u} / \tau_{u e}$ is in the range of $0.81-1.22$, the average is 1.00 , the standard deviation is 0.13 , and the coefficient of variation is 0.13 . Equation 3 has a high degree of fitting to the test points, indicating that it can be used as a reference for actual projects. The positions of the two steel bars in the equation are the same as in this test; they are placed close together, and the diameter of the sleeve is $60-70 \mathrm{~mm}$.

\subsection{Critical lap length}

When bond-slip failure between the steel bar and grouting material occurs simultaneously with steel bar breakage, the lap length is called the critical lap length, The following results can be obtained by equalizing the tensile force of the steel bar and the bonding force around the steel bar.

$\bar{\tau}_{u}=\frac{d f_{u}}{4 \eta l_{c r}}$

where $f_{u}$ is the ultimate tensile strength of the steel bar obtained from the steel material property test, and the reduction coefficient $\eta$ of the effective contact area of the steel bar and the grouting material is taken as 0.9.

From Equations 3 and 4, the formula for the critical lap length of a grouted sleeve lapping connector is obtained as follows:

$l_{\mathrm{cr}}=\left[\frac{f_{u}}{2.76 \eta f_{t}\left(5.89-0.27 \frac{D}{d}+5.84 \frac{t}{D}\right)}-1.52\right] d$

Table 8 presents the comparison of the critical lap length $I_{c r}$ of specimens calculated by Equation 5 and the critical lap length $I_{\text {cre }}$ of the specimens in the test. It can be seen that the calculated and test values are basically the same. This shows that Equation 5 can be used for sleeve design.

Table 8 Comparison between the calculated and experimental value of critical lapping length

\begin{tabular}{ccccc}
\hline $\begin{array}{c}\text { Diameter of sleeve } \\
(/ \mathrm{mm})\end{array}$ & \multicolumn{2}{c}{ Thickness of sleeve } & $\begin{array}{c}\text { Diameter of Steel bar } \\
(/ \mathbf{m m})\end{array}$ & \multicolumn{2}{c}{ Critical lap length } \\
\cline { 3 - 5 } & \multirow{3}{*}{3.5} & 20 & 239 & 200 \\
\hline 79 & & 22 & 260 & 220 \\
& & 25 & 272 & $250 \sim 313$ \\
\hline
\end{tabular}

\section{CONCLUSION}

1. When the lap lengths are same, the larger the diameter of the steel bar, the larger the contact area between the steel bar and the grouting material, and the higher the ultimate bearing capacity of the specimen. When the diameter of the steel bar remains the same, when slip failure occurs (the lap length of steel bar is $10 \mathrm{~d}$ or less), the bearing capacity of the specimen increases with the lap length. The load-bearing capacity of the specimen is basically the same when the failure mode is steel bar pull-out.

2. For a given steel bar diameter, the larger the lap length, the greater the initial stiffness of the specimen (slightly less than the stiffness of the steel material), and the greater the elongation ratio and displacement ductility coefficient under the maximum force of the specimen. 
3. The longitudinal strain of the half-length section of the sleeve is the tensile strain in the early stage of loading, which gradually transforms to compressive strain as the load increases. For a given steel bar diameter, the longitudinal tension-compression transition load of the sleeve gradually increases with the lap length. During the loading process, the longitudinal tensile strain of the sleeve near the steel bar increases with the lap length, and the longitudinal compressive strain of the sleeve at the far steel bar side decreases as the lap length increases under the ultimate load.

4. At the initial stage of loading, the half-length section of the sleeve is subjected to circumferential compression near the side of the steel bar, and the circumferential direction gradually changes to tensile strain in later stages of loading. The greater the lap length of the specimen, the greater the compression-tension transition load. In the early stage of loading, the circumferential strain at the edge of the sleeve is greater than at the middle section. Under the ultimate load, the grouting material at the end falls off, and the circumferential strain in the middle of the sleeve is greater than at the edge section.

5. Given the force transmission path of the connector, based on the typical steel-concrete bonding force distribution curve, the longitudinal stress distribution and development process of the sleeve were analyzed, and it was concluded that the sleeve is longitudinally tensioned at the initial stage of loading and longitudinally compressed at the later stage. This is consistent with test results, which show that the longitudinal force on the side of the steel bar on the sleeve is greater than that on the side of the far steel bar, which accords with the viewpoint that the closer the distance between the steel bar and the sleeve, the greater the force on the sleeve.

6. Based on the test data, an equation for the ultimate bond strength of the connector was fitted, and an equation to calculate the critical lap length of the sleeve was proposed.

\section{ACKNOWLEDGMENTS}

We thank thanks Prof Xilin Lv (University of Tongji) for his assistance and LetPub (www.letpub.com) for its linguistic assistance during the preparation of this manuscript.

Authors contribution: Conceptualization, Q Yu; Data curation, Q Yu; Formal Analysis, Q Yu; Methodolagy, Q Yu; Project administration, Q Yu; Writing-review\&editing, Q Yu, L Zhang; Writing-original draft, L Zhang; Visualization, L Zhang, Investigation, P Tang; Supervision, L Li; Funding acquisition, X Zhang, B Fan, Z Zhang, Z Chen.

Editor: Marcílio Alves

\section{References}

Alias, A., et al. (2013) Structural Performance of Grouted Sleeve Connectors with and without Transverse Reinforcement for Precast Concrete Structure. Procedia Engineering 53: p. 116-123.

Ameli, M.J., Parks, J.E, Brown, D.N, Pantelides, C.P (2015) Seismic evaluation of grouted splice sleeve connections for reinforced precast concrete column-to-cap beam joints in accelerated bridge construction. $\mathrm{PCl}$ journal 60(2): p. 80-103.

American Concrete Institute. ACl 318-1999 Building Code Requirements for Structural Concrete and Commentary. 1999. American Concrete Institute Committee.

BS, Structure use of concrete-Part 1: Code of practice for design and construction. 1997.

Bureau of Quality and Technical Supervision of the People's Republic of China. Method of testing cements-determination of strength(ISO method): GB/T 17671-1999[S]. Beijing: China Standard Press, 1999.

China, M.O.C.O., General Administration of Quality Supervision. Code for design of concrete structures. 2010, China Building Industry Press: Beijing.

EINEA, A., T. YAMANE and M.K. TADROS (1995) Grout-filled pipe splices for precast concrete construction. PCl journal 40(1): p. 82-93.

Henin, E. and G. Morcous (2015) Non-proprietary bar splice sleeve for precast concrete construction. Engineering structures 83: p. 154-162. 
Holden, T., J. Restrepo and J.B. Mander (2003) Seismic Performance of Precast Reinforced and Prestressed Concrete Walls. Journal of structural engineering (New York, N.Y.) 129(3): p. 286-296.

Hosseini, S.J.A. and A.B.A. Rahman (2016) Effects of spiral confinement to the bond behavior of deformed reinforcement bars subjected to axial tension. Engineering structures 112: p. 1-13.

Hosseini, S.J.A., et al. (2015) Bond behavior of spirally confined splice of deformed bars in grout. Construction and Building Materials 80: p. 180-194.

Lin, F. and X. Wu (2016) Mechanical Performance and Stress-Strain Relationships for Grouted Splices Under Tensile and Cyclic Loadings. International Journal of Concrete Structures and Materials 10(4): p. 435-450.

Ling, J.H., Rahman, A.B.A., Mirasa, A.K. and Hamid, Z.A. (2008a) Performance of cs-sleeve under direct tensile load part 1 failure modes. Malaysian Journal of Civil Engineering 20(1): p. 89-106.

Ling J.H., Rahman, A.B.A. and Mirasa, A.K. (2008b) Performance of cs-sleeve under direct tensile load part Ilstructural performance. Malaysian Journal of Civil Engineering 20(1): p. 107-127.

Ling, J.H., A.B. Abd. Rahman and I.S. Ibrahim (2014) Feasibility study of grouted splice connector under tensile load. Construction and Building Material 50: p. 530-539.

Ling, J.H., et al. (2012) Behaviour of grouted pipe splice under incremental tensile load. Construction and Building Materials 33: p. 90-98.

Liu, Y., Zhou, B., Cai, J., Lee, D.S., Deng, X., Feng, J. (2018) Experimental study on seismic behavior of precast concrete column with grouted sleeve connections considering ratios of longitudinal reinforcement and stirrups. Bulletin of Earthquake Engineering 16(12): p. 6077-6104.

Lu, Z., Wang, Z., Li, J., Huang, B. (2017) Studies on Seismic Performance of Precast Concrete Columns with Grouted Splice Sleeve. Applied sciences 7(6): p. 571.

Ministry of Construction of The People's Republic of China, G.A.O.Q., Code for Seismic Design of Buildings. 2010, China Architecture\&Building Press: Beijing.

Ministry of Housing and Urban-Rural Construction of the People's Republic of China. Technical specification for grout sleeve splicing of rebars: JGJ 355-2015[S]. Beijing: China Building Industry Press, 2015.

Popa, V., Papurcu, A., Cotofana, D., Pascu, R. (2015) Experimental testing on emulative connections for precast columns using grouted corrugated steel sleeves. Bulletin of Earthquake Engineering 13(8): p. 2429-2447.

Sayadi, A.A., Abd. Rahman, A., Sayadi, A., Bahmani, M, Shahryari, L (2015) Effective of elastic and inelastic zone on behavior of glass fiber reinforced polymer splice sleeve. Construction and Building Materials 80: p. 38-47.

Sayadi, A.A., Rahman, A.B.A., Jumaat, M., Johnson Alengaram, U, Ahmad, S. (2014) The relationship between interlocking mechanism and bond strength in elastic and inelastic segment of splice sleeve. Construction and Building Materials 55: p. $227-237$.

Seyed, J.A.H. and B.A.R. Ahmad (2013) Analysis of spiral reinforcement in grouted pipe splice connectors. Građevinar (Zagreb) 65(6): p. 537-546.

Walker, P.R., M.K. Batayneh and P.E. Regan (1997) Bond strength tests on deformed reinforcement in normal weight concrete. Materials and structures 30(7): p. 424-429.

Wang, Z., Qu, H., Li, T., Wei, H., Wang, H., Duan, H., Jiang, H. (2018) Quasi-static cyclic tests of precast bridge columns with different connection details for high seismic zones. Engineering Structures 158: p. 13-27.

Wu, D., Liang, S., Guo, Z., Zhu, X., Fu, Q. (2016) The development and experimental test of a new pore-forming grouted precast shear wall connector. KSCE Journal of Civil Engineering 20(4): p. 1462-1472.

Xu, L., J. Pan and J. Cai (2019) Seismic performance of precast RC and RC/ECC composite columns with grouted sleeve connections. Engineering Structures 188: p. 104-110.

Xu, Y. (1990) Experimental Study on Bond and Anchorage Behavior Between Concrete and Deformed Rebars. Beijing: Tsinghua University.

Xu, Y., H. Wang and W. Shen (1993) Experimental on force transferring properties of overlapped bars. Building Structure (4):20-24.

Yee, A.A. (1968) splice sleeve for reinforcing bars. U.S. Patent 3,540,763. 
Yee, A.A. (2001) Structural and Economic Benefits of Precast/Prestressed Concrete Construction. PCI journal 46(4): p. $34-42$.

Yu, Q. and Z. Xu (2017) Experimental study of grouted sleeve lapping connector under tensile load. Građevinar (Zagreb) 69(6): p. $453-465$.

Yu, Q. (2014) Grouted Sleeve Lapping Connector. ZL 20142 0656653.0.2015.04.01.

Yu, Q., Sun, J., Xu, Z., Li, L., Zhang, Z., Yu, S. (2019) Mechanical Analysis of Grouted Sleeve Lapping Connector. Applied sciences $9(22):$ p. 4867.

Yu, Q., Xu, K., Xu, Z., Fang, Y., Lu, X. (2016) Seismic behavior of precast shear walls with vertical reinforcements overlap grouted in constraint sleeve. Rev. Téc. Ing. Univ. Zulia 39(6): p. 207-217.

Zheng, Y., Guo, Z., Guan, D., Zhang, X. (2018) Parametric study on a novel grouted rolling pipe splice for precast concrete construction. Construction \& building materials 166: p. 452-463. 